\title{
Consenso de Revascularización de Miembros Inferiores del Colegio Argentino de Cardioangiólogos Intervencionistas $\mathrm{CACl} 2018$
}

\author{
Consensus of Lower Limbs Revascularization from Argentinian Collegue \\ of Interventional Cardioangiologist - CACl 2018
}

\section{Autores:}

Coordinadores: Dr. Andrés Dini, Dr. Daniel Mauro

Comité de Redacción: Dr. Alberto Tamashiro, Dr. Jorge Bluguermann, Dr. Fernando Belcastro, Dr. Pablo Elissamburu, Dr. Ignacio Bluro, Dr. Nicolás González, Dra. Ana Mollón, Dr. Maximiliano Rossi, Dr. Alejandro Álvarez lorio, Dr. Marcelo Agüero, Dr. Pablo Liva, Dr. Gerardo Nau, Dr. Ernesto Torresani, Dr. Esteban Mendaro, Dr. Mariano Ferreira, Dr. Gustavo Tamashiro.

Comité de Revisión: Dr. José Amadeo Álvarez, Dr. Dionisio Chambré, Dr. Carlos Rojas Matas, Dr. Juan Manuel Ponce, Dr. Alejandro Delacasa, Dr. Arturo Fernández Murga

Revista Argentina de Cardioangiología Intervencionista 2018;9(3):136-161. Doi: 10.30567/RACI/20183/0136-0161

\section{ÍNDICE}

\section{Abreviaturas}

AAA: Aneurisma de Aorta Abdominal

ACC-AHA: American College of Cardiology - American Heart Association

ACV: Accidente Cerebrovascular

AE: Auto-expandible

AFC: Arteria Femoral Común

AFS: Arteria Femoral Superficial

AG: Acceso Anterógrado

AH: Arteria Hipogástrica

AI: Aorto-Ilíaco

AIC: Arteria Ilíaca Común

AIE: Arteria Ilíaca Externa

Angio-RM: Angiografía por Resonancia Magnética

Angio-TC: Angiografía por Tomografía Computada

APer: Arteria Peronea

AP: Arteria Poplítea

APe: Arteria Pedia

APL: Arco Plantar

AR: Acceso Retrógrado

ATA: Arteria Tibial Anterior

ATP: Angioplastia Transluminal Percutánea

ATPo: Arteria Tibial Posterior

CACI: Colegio Argentino de Cardioangiólogos Intervencionistas

CI: Claudicación Intermitente

CL: Contralateral

$\triangle$ Correspondencia: Dr. Daniel Mauro, Avda El Libertador 950, $4^{\circ}$ piso, CP 5600, San Rafael, Mendoza. Argentina. Email: dmauro@intramed.net;

Dr. Andrés Dini, Beruti 2374, CP 1117, Ciudad Autónoma de Buenos Aires, Argentina. Email: andresedini@gmail.com

Los autores no declaran conflictos de intereses

Recibido: 23/08/2018 |Aceptado: 02/09/2018
ClCr: Clearance de Creatinina

DBT: Diabetes

DEB: Balón Liberador de Drogas

DES: Stent Liberador de Drogas

EAP: Enfermedad Arterial Periférica

EB: Expandible por Balón

EE. UU.: Estados Unidos de Norteamérica

ES: Ejercicios Supervisados

EVP: Enfermedad Vascular Periférica

FDA: Food and Drug Administration

FP: Femoro-poplíteo

HTA: Hipertensión Arterial

ICM: Isquemia Crítica de Miembros Inferiores

ICRM: Isquemia Crónica de Miembros Inferiores

IP: Infra-poplíteo

IR: Insuficiencia Renal

ITB: Índice Tobillo-Brazo

MMII: Miembros Inferiores

OMS: Organización Mundial de la Salud

RIS: Restenosis Intrastent

RLB: Revascularización de Lesión Blanco

TASC: Trans-Atlantic Inter- Society Consensus

TBQ: Tabaquismo

TMO: Tratamiento Médico Óptimo

TTP: Tronco Tibioperoneo

TDC: Trombolisis Dirigida por Catéter

US: Ultrasonido

\section{Introducción}

1.1 Epidemiología y estado actual

1.2 Abordaje Clínico de la Enfermedad Vascular Periférica

2. Estudios Complementarios Diagnósticos No Invasivo

2.1 Índice Tobillo-Brazo

2.2 Ecografía Doppler

2.3 Angiografía por Resonancia Magnética

2.4 Angiografía por Tomografía Computada 
3. Diagnóstico Invasivo

4. Rol del Tratamiento Médico

4.1 Tratamiento antiplaquetario

4.2 Tratamiento post revascularización

5. Angioplastia en Territorio Aorto-Ilíaco

5.1 Consideraciones generales de la ATP en territorio Aorto-Ilíaco

5.2 Tipo de stent: balón expandible vs auto expandible

6. Angioplastia en Territorio Femoro-Poplíteo

6.1 Consideraciones Generales

6.2 Tratamiento mediante balón convencional

6.3 Tratamiento mediante stent convencional

6.4 Tratamiento mediante stent liberador de droga (DES)

6.5 Tratamiento mediante Angioplastia con Balón Liberador de Droga (DEB)

6.6 Tratamiento de lesiones complejas (TASC II Cy D)

6.7 Tratamiento de la reestenosis intrastent en sector Femoro-Poplíteo

7. Angioplastia en Territorio Infrapatelar:

7.1 Introducción

7.2 Indicaciones de revascularización

7.3 Objetivos hemodinámicos

7.4 Sitios de abordaje

7.5 Complejidad de las lesiones

7.6 Dispositivos elegibles

7.7 Abordaje de las arterias del pie

7.8 Pie Diabético

8. Tratamiento en isquemia crítica de Miembros Inferiores

9. Angioplastia en segmentos de flexo-compresión

10. Indicaciones para la revascularización quirúrgica

11. Anexo I: Técnicas y recomendaciones para el ITB

12. Anexo II: Nuevos abordajes: Accesos no convencionales para angioplastia de miembros inferiores.

13. Anexo III: Alternativas Endovasculares frente al fracaso de las técnicas quirúrgicas.

13.1 Trombolisis

13.2Tromboaspiración

13.3 Trombectomía mecánica

14. Anexo IV: Tratamiento endovascular de la enfermedad aneurismática de miembros inferiores.

\section{INTRODUCCIÓN}

Desde los inicios de la Hemodinamia en el país, los miembros del Colegio han efectuado, además de los estudios cardiológicos, procedimientos periféricos. Durante más de cuarenta años, el número de casos en las diversas patologías permitió adquirir suficiente conocimiento como para reunir las experiencias de los miembros colegiados del país y aunar criterios para la elaboración de un Consenso que involucre todos los aspectos científicos, académicos y prácticos en el manejo de esta patología.

Así, este Consenso pretende no solo ser una guía útil para la toma de decisiones por parte del intervencionista, sino y por sobre todo ser una herramienta de consulta para el amplio espectro de especialidades que confluyen en la identificación y tratamiento de pacientes con Enfermedad Vascular Periférica.

A cada una de las indicaciones o intervenciones terapéuticas propuestas se le asigna un nivel de Recomendación (Clase 1, ll, lla, llb y lll) y nivel de evidencia (A, B y C), universalmente aceptado. El nivel de Recomendación clase I señala que el beneficio supera claramente al riesgo, indicando que el tratamiento, intervención o estrategia debería de implementarse. El nivel de Recomendación clase II indica que el beneficio supera al riesgo, se interpreta como IIa si es razonable implementar el tratamiento, intervención o estrategia, y IIb cuando en ocasiones pueden considerarse estas medidas. En el nivel de Recomendación clase III el tratamiento, intervención, o estrategia no deben administrarse o instrumentarse por ausencia de beneficio o daño.

En el nivel de evidencia A los datos provienen de múltiples estudios clínicos aleatorizados o randomizados de grandes dimensiones o meta-análisis, en el nivel de evidencia B los datos derivan de un solo estudio clínico aleatorizado o de estudios clínicos no aleatorizados, y el nivel de evidencia $\mathbf{C}$ lo aporta el consenso de opinión de expertos o referentes.

Finalmente, confiamos también en que este Consenso brinde a los distintos actores del sistema de salud un acceso simplificado a los nuevos dispositivos de tecnología médica, sus recomendaciones probadas y beneficios terapéuticos esperados con el uso racional de los mismos, adaptados a la realidad asistencial de nuestro medio.

No por ser obvio dejaremos de mencionar que el rápido avance de las técnicas y dispositivos para el tratamiento en este territorio nos deja desde ya comprometidos en una pronta y permanente actualización de este Consenso.

\subsection{Epidemiología y estado actual}

La enfermedad arterial periférica (EAP) se refiere a la aterosclerosis que afecta la irrigación de los miembros inferiores (MMII). Es la patología menos reconocida en relación con otras afecciones ateroscleróticas como la coronaria y cerebrovascular.

Estudios epidemiológicos indican que alrededor de $7.1 \mathrm{mi}-$ llones de personas tienen EAP en EE.UU ${ }^{1}$. La edad es un factor de riesgo importante: La Encuesta Nacional de Examen de Salud y Nutrición de EEUU ${ }^{2.3}$ (National Health and Nutrition Examination Survey) refiere una prevalencia de EAP del 5.9\% en participantes de 40 años o más, que asciende a un $15-20 \%$ en los mayores de 65 años. El Estudio German Epidemiological Trial on Ankle Brachial Index (GET $A B I)$ refiere en un grupo de 6990 pacientes no seleccionados $\geq 65$ años una frecuencia de EAP del $20 \%$ en los hombres y $17 \%$ en las mujeres, siendo infrecuente antes de los 40 años ${ }^{4}$. El estudio PARTNERS (PAD Awareness, Risk, and Treatment: New Resources for Survival), que incluyó 6979 pacientes en 350 centros de salud de EEUU realizó un cribado del índice tobillo-brazo (ITB) a personas mayores de 70 años, o mayores de 50 años si eran tabaquistas o diabéticos ${ }^{5}$. En el 29\% se diagnosticó EAP en MMII, de los cuales sólo el $11 \%$ presentaban síntomas típicos. A pesar de la relativa frecuencia de enfermedad la mayoría de los pacientes se encuentran asintomáticos. El grupo asintomático es tres a cuatro veces mayor que el grupo sintomático con claudicación intermitente.

La prevalencia en los diabéticos ronda el $27 \%$. Su frecuencia se incrementa con la edad y es más frecuente en el sexo masculino, tendencia que se va equilibrando con la edad en la raza negra ${ }^{2-3}$. En nuestro país no disponemos de datos en cuanto a prevalencia, sin embargo, se estima en alrededor del $28.7 \%$ en países de medianos o bajos ingresos como el nuestro.

Las lesiones arteriales por arteriosclerosis de los miembros inferiores no constituyen una condición local, sino una ma- 
nifestación sistémica generalmente subdiagnosticada ${ }^{8}$. La coexistencia de la patología vascular cerebral, la cardiopatía isquémica y la oclusión arterial periférica, es un marcador de incremento de riesgo de eventos cardiovasculares fatales y no fatales ${ }^{1,6}$. El riesgo es mayor dentro del año de iniciado la claudicación intermitente $(\mathrm{CI})^{6}$. Si bien resulta más probable que ocurra un evento vascular cerebral o un infarto de miocardio no fatal en el primer año antes que una amputación mayor por isquemia de miembros inferiores se observa que la mortalidad proyectada en claudicantes alcanza al $30 \%$ a los cinco años, $50 \%$ a los diez años y $70 \%$ a los 15 años ${ }^{6}$.

Los factores de riesgo para la EAP son similares a los de la enfermedad coronaria: edad, tabaquismo (TBQ), diabetes (DBT), hipertensión arterial (HTA), dislipemia (DLP), insuficiencia renal crónica (IRC) ${ }^{7}$.

La expectativa de vida decrece en diez años aún en ausencia de infarto de miocardio o stroke ${ }^{8}$.

El TBQ es un factor de riesgo importante para la progresión de la arteriopatía, incrementando el riesgo de amputación 11 veces con respecto a los no fumadores. La DBT es otro factor de riesgo importante especialmente en la patología Infrapatelar ${ }^{6}$. La IRC resulta un predictor independiente del incremento de la morbilidad y mortalidad cardiovascular incluyendo la amputación del miembro ${ }^{9}$.

En el siglo XXI, la EAP de MMII se ha convertido en un problema global con consecuencias sociales y económicas. Epidemiológicamente se considera una pandemia, con un incremento del $29 \%$ en la última década en las clases sociales de bajos y moderados recursos y de un $13 \%$ en la de altos ingresos.

Los gobiernos, las organizaciones no gubernamentales y el sector privado deben abordar y evaluar las mejores estrategias para el diagnóstico, tratamiento óptimo y especialmente la prevención de esta enfermedad.

\section{Conclusiones 1:}

Basado en la evidencia epidemiológica, la población en riesgo para EAP en MMII se define por:

- Edad < de 50 años con DBT + un factor de riesgo: TBQ, DLP, HTA o hiperhomocisteinemia

- Edad entre 50 - 69 años fumadores o diabéticos

- $\quad$ Edad $\geq$ de 70 años

- Pacientes claudicantes o dolor isquémico de reposo

- Trastorno del pulso al examen de miembros inferiores

- Arteriopatía coronaria, carotídea o renal conocida

\section{Conclusiones 2:}

- La historia natural de la EAP como manifestación de una enfermedad sistémica suele ser lenta y progresiva, lo que erróneamente induce a pensar que su evolución puede ser benigna.

- A pesar de la relativa frecuencia de la enfermedad la mayoría de los pacientes se encuentran asintomáticos, por lo que epidemiológicamente se le ha prestado poca atención.

- La frecuencia de EAP es más alta en los pacientes con DBT, TBQ, HTA, IRC, edad avanzada, lesiones coronarias y lesiones cerebrales. Es importante el rol de los cardiólogos y clínicos para la detección de la enfermedad periférica de miembros inferiores generalmente subdiagnosticada ${ }^{8}$.

- El tratamiento agresivo de los factores de riesgo para arterosclerosis es mandatorio a los efectos de mejorar la calidad de vida ${ }^{7,9}$.

\subsection{Abordaje clínico de la Enfermedad Vascular Periférica}

\section{Anamnesis - Presentación Clínica}

El diagnóstico de la EAP comienza con la sospecha clínica en pacientes con antecedentes sugestivos de aterosclerosis sistémica y de las extremidades. La sospecha clínica debe ser más alta en personas mayores de 65 años, en pacientes con aterosclerosis coronaria o cerebral conocida, y aquellos con factores de riesgo aterosclerótico.

El abordaje se debe iniciar por el estudio de las condiciones generales cardiovasculares asociadas y luego por el diagnóstico diferencial. Posteriormente se deben evaluar: 1- la severidad de la patología, 2- presencia o no de dolor, 3- dolor de esfuerzo o de reposo, 4- el estado del miembro, 5- los estudios a realizar, 6- el eventual tratamiento médico o de revascularización ${ }^{7}$.

La CI es el síntoma más frecuente. Se define en el cuestionario de Rose ${ }^{10}$, como la aparición de un dolor muscular durante el ejercicio. El síntoma puede ser una sensación de malestar, quemazón, pesadez, tensión, opresión o calambre y suele originarse en un compartimento muscular, como la pantorrilla, el muslo, la cadera o la nalga, y no en una articulación. Al interrumpir una actividad física, la reducción del trabajo muscular re equilibra el flujo sanguíneo disponible con la demanda muscular, y el dolor cede con rapidez. Son puntos importantes en el interrogatorio: el tiempo de caminata, la distancia hasta el inicio del dolor y la máxima distancia sin detenerse a pesar del dolor. Esto nos permite definir el grado de claudicación utilizando sistemas de clasificación como el sistema de Rutherford y de Fontaine (tablas 1 y 2).

\begin{tabular}{|c|c|}
\hline CATEGORÍA & ESTADIO \\
\hline 0 & Asintomático \\
\hline 1 & Claudicación leve \\
\hline 2 & Claudicación moderada \\
\hline 3 & Claudicación grave \\
\hline 4 & Dolor en reposo \\
\hline 5 & $\begin{array}{l}\text { Pérdida ligera de tejido: úlcera no cicatrizante, gangrena } \\
\text { focal con úlcera difusa del pie. }\end{array}$ \\
\hline 6 & $\begin{array}{l}\text { Pérdida importante de tejido que se extiende por encima } \\
\text { del nivel transmetatarsiano, pie funcional ya irrecuperable. }\end{array}$ \\
\hline \multicolumn{2}{|c|}{ Tabla 2. Clasificación de Fontaine. } \\
\hline I & Asintomático, ITB <0.9 \\
\hline II & Claudicación intermitente \\
\hline Ila & Claudicación intermitente $>150$ mts \\
\hline Ilb & Claudicación intermitente $<150$ mts \\
\hline III & Dolor en reposo \\
\hline IV & Necrosis tisular focal \\
\hline
\end{tabular}

El estudio PARTNER demostró que sólo el 10\% de los pacientes con EAP referían CI típica y un 40\% síntomas atípicos. La aplicación de los cuestionarios de claudicación, como el de la Organización Mundial de la Salud (OMS), Rose o el Walking Impairment Questionnaire ${ }^{10-11}$, pueden subestimar la prevalencia de EAP en un 50\%. Datos de McDermott y col. indican que son frecuentes otros síntomas distintos a la claudicación, demostrando que los pacientes con EAP tienen varios tipos de malestares: dolor en reposo y al andar; dolor sólo al andar, que obligaba a detener la actividad y dolor que les permitía seguir andando. Esta variedad de presentaciones pasa inadvertida si sólo se pregunta por los síntomas 
típicos. Las actuales guías europeas introducen el concepto de "claudicación enmascarada" para la presencia de síntomas atípicos tales como parestesias, sensación de pesadez, ardor en la planta del pie, etc. ${ }^{183} \mathrm{~A}$ pesar de esto, la calidad del dolor, típica o atípica, no predice el grado de disminución de la presión de perfusión de la extremidad determinado mediante el ITB ${ }^{12-13-14}$.

\section{Examen Clínico}

1- Observación: coloración, ausencia de vello, engrosamiento y fragilidad de las uñas, atrofia muscular, lesiones tisulares, úlceras y gangrenas. Las úlceras arteriales son muy dolorosas, se visualizan en punta de dedos y o en zonas de presión, con base pálida y bordes irregulares.

2-Exploración estática: valorar la diferencia de temperatura, explorar la simetría de pulso con palpación.

3- Exploración dinámica: cambio de color de la piel con el miembro en posición elevada a $45-60^{\circ}$ durante 1 minuto: es anormal si la palidez es inmediata (10-15 segundos). Después de 1 minuto, el paciente se sienta ubicando la extremidad en posición declive y se registra el tiempo de relleno venoso pedio. El relleno normal es inmediato (10-15 seg.). El retraso del relleno venoso o la aparición de adormecimiento de más de 1 minuto indican EAP de MMII avanzada. La dilatación arteriolar y venular causada por la isquemia puede generar un color violáceo del pie en posición declive, denominado rubor postural.

\section{Diagnóstico diferencial de la claudicación intermitente}

En la claudicación con el esfuerzo, se debe tener en cuenta los diagnósticos diferenciales vasculares y no vasculares, como puede resumirse a continuación:

$$
\begin{aligned}
& \text { Causas no ateroscleróticas de dolor de esfuerzo } \\
& \text { Causas obstructivas arteriales no ateroscleróticas. } \\
& \text { Ateroembolia } \\
& \text { Arteritis } \\
& \text { Displasia fibromuscular } \\
& \text { Endofibrosis de la arteria iliaca externa } \\
& \text { Compresión extravascular } \\
& \text { Compresión de la arteria poplítea } \\
& \text { Quistes en adventicia } \\
& \text { Causas no obstructivas arteriales } \\
& \text { Claudicación venosa } \\
& \text { Síndrome compartimental } \\
& \text { Radiculopatía lumbar } \\
& \text { Estenosis vertebral (¿radiculopatía?) } \\
& \text { Artrosis de cadera / rodilla } \\
& \text { Miositis } \\
& \text { Otras }
\end{aligned}
$$

La compresión de la arteria poplítea afecta en general a personas muy activas o deportistas. El origen anómalo del músculo gastrocnemio (gemelo) interno puede comprimir la arteria Poplítea al andar y causar síntomas de claudicación. La Endofibrosis de la Arteria Iliaca externa, un trastorno relativamente infrecuente observado en ciclistas que entrenan mucho y en otros deportistas de alto rendimiento, puede causar claudicación.

La Displasia Fibromuscular es una enfermedad oclusiva arterial no ateroesclerótica, no inflamatoria, localiza- da con mayor frecuencia en la arteria Renal y en la arteria Carótida, aunque puede afectar a otros territorios arteriales. En los lechos vasculares de las extremidades inferiores es más frecuente sobre las arterias Iliacas. Puede afectar a la capa íntima, media o adventicia, pero es más frecuente sobre la capa media. Se diagnostica por la imagen "en collar de perlas" en la angiografía y por su predilección por los segmentos no ramificados de los vasos. Su causa se desconoce.

El aumento del tamaño de los músculos de la pantorrilla durante el ejercicio puede dificultar el retorno venoso, lo que provoca síndrome compartimental de esfuerzo -aumento de la presión tisular y disminución del flujo microvascular- y causa dolor u opresión en la pantorrilla con el esfuerzo. Los síntomas mejoran si se coloca la extremidad inferior en posición elevada al acabar el ejercicio.

La claudicación venosa puede ser consecuencia de trombosis ilio-femoral con escasa circulación venosa colateral. Cuando el retorno venoso está alterado, el aumento del flujo arterial por el ejercicio incrementa mucho la presión venosa y produce una sensación intensa de opresión o de estallido en la extremidad. Estos pacientes tienen con frecuencia edema en la extremidad inferior.

\section{ESTUDIOS COMPLEMENTARIOS DIAG- NÓSTICOS NO INVASIVOS}

\section{1 Índice tobillo-brazo (ITB)}

Técnica: una descripción detallada de la técnica puede encontrarse en el Anexo I

El valor para estratificación de severidad del ITB presenta variaciones en los distintos trabajos ${ }^{11}$. Las cifras que se presentan en la tabla, aproximadamente se correlaciona con los signos y síntomas.

\section{- ITB entre 1 y 1,3 es normal.}

- $\quad$ ITB $<0,9$ tiene sensibilidad de $79 \%$ y especificidad del $\mathbf{9 6} \%$ de correlación con EAP significativa al relacionarlo con la angiografía ${ }^{12}$.

- $\quad$ ITB $>0,5$ sugiere que la progresión a isquemia crítica es improbable durante los próximos 6,5 años de seguimiento ${ }^{13}$.

- $\quad$ ITB $\leq 0,4$ corresponde a pacientes con dolor en reposo por isquemia crítica con úlceras, gangrenas y riesgo de amputación. Es un grupo de alto riesgo.

- $\quad$ ITB $\geq 1,4$ se debe a la falta de compresión arterial a una presión de $250 \mathrm{mmHg}$. por calcificación difusa. Se observan en pacientes con insuficiencia renal severa, DBT y edad avanzada. Son un grupo de alto riesgo; se puede utilizar el índice dedo brazo, para confirmar o descartar el diagnóstico ${ }^{14}$.

Predictor de riesgo mortalidad: Además de su información diagnóstica, el ITB es un predictor independiente de mortalidad cardiovascular (estudio ABI Collaboration).

- $\quad$ ITB $<1$ incidencia de episodios adversos más alta in cluso en ausencia de síntomas.

- $\quad$ ITB $\leq 0,8$ se asocia al doble de mortalidad en 10 años ajustada por edad,

- $\quad$ ITB $<0,4$ se asocia a un aumento del cuádruple de mortalidad $^{15}$

Cuanto más bajo el ITB, más alta la morbilidad y mortalidad cardiovascular ${ }^{15-16}$. 
ITB: concordancia con signos y síntomas

$\begin{array}{lcl}\text { - } & 1.3-1.0 & \text { normal } \\ \text { - } & 0.9-0.5 & \text { claudicación intermitente } \\ \text { - } & 0.5-0.4 & \text { dolor de reposo } \\ \text { - } & 0.4-0.3 & \text { trastornos tróficos ulceración y gangrena } \\ \text { - } \quad>1.4 & \text { no compresible (a una presión }>250 \mathrm{mmHg} \text { ) } \\ \text { Es necesaria una reducción }>\text { del } 70 \% \text { de luz arterial para de- } \\ \text { sarrollar déficit de irrigación tisular. }\end{array}$

\begin{tabular}{|c|c|c|}
\hline Recomendaciones para índice tobillo-brazo & Clase & $\begin{array}{l}\text { Nivel de } \\
\text { evidencia }\end{array}$ \\
\hline $\begin{array}{l}\text { La medición del ITB está indicada como prueba no invasi- } \\
\text { va de primera línea para detectar y diagnosticar enferme- } \\
\text { dad arterial de las extremidades inferiores. }\end{array}$ & I & $B$ \\
\hline $\begin{array}{l}\text { Ante la presencia de ITB > 1,4 en personas diabéticas o } \\
\text { de edad avanzada o con insuficiencia renal crónica, debe } \\
\text { utilizarse otro método diagnóstico. }\end{array}$ & । & B \\
\hline $\begin{array}{l}\text { La medición del ITB con ejercicio debe ser considerada } \\
\text { en el caso de pacientes con síntomas atípicos sugestivos } \\
\text { de EAP con el fin de confirmar el diagnóstico y cuantifi- } \\
\text { car la gravedad. }\end{array}$ & Ila & B \\
\hline $\begin{array}{l}\text { El resultado del ITB debe ser informado como anormal } \\
\text { (ITB } \leq 0,9) \text {, borderline (ITB } 0,91 \text { a } 0,99) \text {, normal (ITB } 1,00 \text { a } \\
1,40) \text {, o no compresible (ITB }>1,40 \text { ) }\end{array}$ & । & C \\
\hline $\begin{array}{l}\text { En pacientes con incremento del riesgo de EAP pero sin } \\
\text { historia clínica o sospecha en el examen físico, la realiza- } \\
\text { ción del ITB es razonable. }\end{array}$ & ॥a & $B$ \\
\hline $\begin{array}{l}\text { El índice del dedo-brazo debe ser considerado para el } \\
\text { diagnóstico en pacientes con sospecha de EAP con ITB } \\
>1,40\end{array}$ & । & $B$ \\
\hline $\begin{array}{l}\text { En pacientes sin riesgo aumentado de EVP y sin historia } \\
\text { clínica o sospecha en el examen físico, la realización del } \\
\text { ITB no está indicado. }\end{array}$ & III & B \\
\hline
\end{tabular}

En nuestro medio se observa una baja utilización del ITB a pesar de ser un método tan económico como eficaz para el diagnóstico y evolución pronóstica. Esto responde en gran medida a la falta de reconocimiento de la práctica por los financiadores de salud pese a encontrarse indicado en las guías nacionales e internacionales con un elevado nivel de evidencia $^{17-23 .}$

\section{Pruebas Funcionales}

Por idénticas razones a las expresadas en el apartado de ITB, lamentablemente también resulta escasa su utilización en nuestro medio. La principal indicación del ITB post ejercicio es en pacientes que se encuentran con sintomatología atípica con ITB en reposo entre 0.9 y 1.40 , asociado a estudios de imágenes no invasivas no concluyentes como la ecografía doppler arterial de miembros inferiores o bien con riesgos aumentados para estudios invasivos. Se utiliza más frecuentemente el protocolo de ejercicio constante (protocolo de Carter), el cual se realiza en una cinta deslizante con una pendiente del $12 \%$ y una velocidad de $3,2 \mathrm{~km} / \mathrm{h}$ durante 5 minutos. Se evalúa la distancia máxima alcanzada, la distancia de aparición de la claudicación y luego se hace nuevamente del ITB post-ejercicio. Es positivo si el descenso de la presión sistólica en tobillo es del $20 \%$ respecto de la basal o si no recupera los valores basales antes de 3 minutos posejercicio ${ }^{17}$. Hay otros protocolos como el de ejercicio gradual de Hiatt o de Gardner donde aumentan la velocidad y/o la pendiente ${ }^{18}$.

\begin{tabular}{|c|c|c|}
\hline $\begin{array}{l}\text { Recomendaciones para la realización de pruebas fun- } \\
\text { cionales }\end{array}$ & Clase & $\begin{array}{l}\text { Nivel de } \\
\text { evidencia }\end{array}$ \\
\hline $\begin{array}{l}\text { Los pacientes con claudicación con ITB entre } 0,90 \text { y 1,40 } \\
\text { deben valorarse por medio de ITB post ejercicio. }\end{array}$ & I & B \\
\hline $\begin{array}{l}\text { En pacientes con EAP y un ITB }<0,90 \text {, la prueba de es- } \\
\text { fuerzo puede ser usada para valorar el estatus funcional. }\end{array}$ & lla & B \\
\hline
\end{tabular}

\subsection{Ecografía Doppler}

La mayoría de los laboratorios vasculares realizan ecografía Doppler de las extremidades. El mismo combinado con el ITB nos brinda la información necesaria para el manejo de la mayoría de los pacientes y nos confirma el diagnóstico con información acerca de la anatomía. Tiene una sensibilidad del $85-90 \%$ y una especificidad mayor del $95 \%{ }^{19}$. La ecografía dúplex utiliza la imagen bidimensional y el Doppler color para localizar la lesión y la onda del Doppler pulsado para cuantificar, mediante la medición de la velocidad de pico sistólico y la relación con la velocidad en zonas sin lesiones, el porcentaje de estenosis. La combinación con el ITB aporta información necesaria para el diagnóstico, tratamiento y pronóstico ${ }^{20,21}$. La ecografía Doppler es menos precisa en las zonas de placa calcificada por la sombra acústica que se genera. Es más difícil diagnosticar las estenosis en serie porque el diagnóstico está basado en la comparación de las velocidades máximas entre segmentos adyacentes, y la hemodinamia está alterada entre estenosis en serie. También utilizamos a la ecografía Doppler para el seguimiento postoperatorio de bypass y posintervencionismo endoluminal con stent o balón.

Si bien algunos estudios unicéntricos ${ }^{22-23}$ sugieren que la ecografía Doppler con buena calidad, realizada en centros de gran experiencia, puede resultar útil como prueba de imagen única para planificar la revascularización periférica tanto percutánea como quirúrgica, sin la necesidad de un segundo método de diagnóstico no invasivo como la Angio-TC, Angio-RM. En nuestra opinión, esta sugerencia no debe ser tomada en cuenta dado que resulta muy difícil contar con la precisión anatómica suficiente como para planificar una revascularización.

Como conclusión entonces, si bien la ecografía Doppler es una herramienta diagnóstica y pronóstica (sobre todo asociada a ITB), no resulta suficiente como único método para la planificación terapéutica.

\subsection{Angiografía por Resonancia Magnética}

La angiografía por resonancia magnética (Angio-RM) ha reemplazado en casos a procedimientos angiográficos invasivos, reduciendo el costo y los riesgos asociados ${ }^{24,25}$. La evaluación de la enfermedad arterial periférica con Angio-RM permite evaluar segmentos largos de la anatomía vascular desde el abdomen hasta el tobillo. Las secuencias dinámicas en tiempos T1 3D con contraste, en conjunto con el movimiento rápido de la camilla en el momento de la adquisición de las imágenes, permiten obtener imágenes de todo el árbol arterial. La evaluación de la enfermedad arterial periférica con Angio-RNM permite realizar imágenes de las tres regiones de ambos MMII: aorto-ilíaca, femoropoplítea e infrapatelar ${ }^{26}$. La Angio-RNM identifica correctamente la enfermedad significativa de la arteria poplítea con sensibilidad del $94 \%$ y especificidad del $92 \%$ y de las arterias tibiales con sensibilidad del $100 \%$ y especificidad de $84 \%$, demostran- 

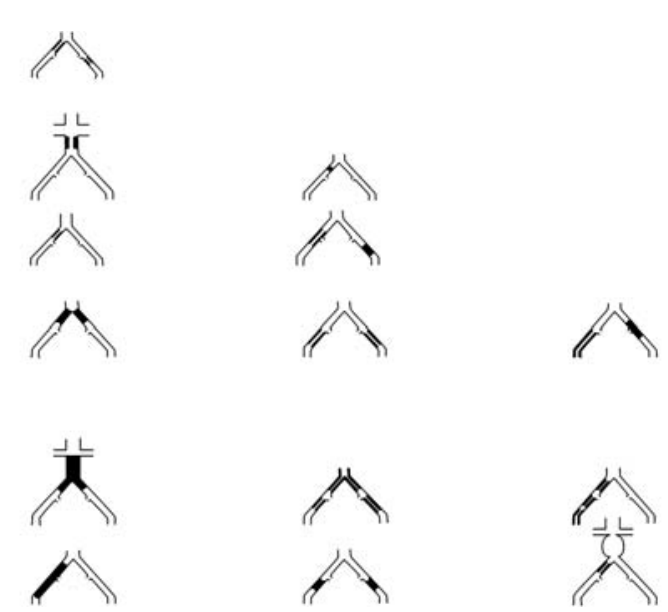

Figura 1: Inter-Society Consensus for the Management of Peripheral Arterial Disease (TASC). Clasificación de lesiones aorto-ilíacas. AAA: Aneurisma de Aorta Abdominal; AFC: Arteria Femoral Común; AlC: Arteria llíaca Común; AlE: Arteria lliaca Externa; AH: Arteria Hipogástrica. Tomado de: Journal of Vascular Surgery 2007 45, S5-S67DOI: (10.1016/j.jvs.2006.12.037)

do mejor certeza diagnóstica en los segmentos infrapatelares en relación con la Angio-TC ${ }^{27}$. La utilización del gadolinio en pacientes con insuficiencia renal crónica (índice de filtrado glomerular $<30 \mathrm{~mL} / \mathrm{min}$ ) constituye una contraindicación absoluta para este método. Otra desventaja que presenta la Angio-RNM es que sobreestima el grado de las lesiones y más aún (hasta un 30\%) en lesiones sobre injerto venoso ${ }^{28,29}$, además de ser tecnología y operador dependiente. Algunos autores han propuesto que la optimización de técnicas de imagen como la Angio-RNM tridimensional (3D) podría en el futuro utilizarse como método único de evaluación previo a la revascularización ${ }^{30}$. Esto no resulta hoy universalmente aceptado y tampoco cuenta con amplia aplicabilidad en nuestro medio, limitándose sólo a casos excepcionales. En nuestra opinión no reemplaza a la angiografía con sustracción digital.

\subsection{Angiografía por Tomografía Computada}

Junto con la Angio-RM su utilización en la evaluación de la patología arterial periférica se encuentra en crecimiento exponencial por ser técnicas no invasivas con excelente determinación anatómica de las arterias periféricas ${ }^{31}$. La angiografía por tomografía computarizada multicorte (Angio-TC) presenta sensibilidad del $95 \%$ y especificidad del 96\% para diagnosticar estenosis/oclusión y ausencia de estenosis significativa en los segmentos aortoilíacos y femoropoplíteos, pero su rendimiento diagnóstico es menor en el trayecto infrapatelar ${ }^{32,33}$. Como desventajas podemos mencionar: dificultad de valorar correctamente lesiones altamente calcificadas; riesgo de nefropatía inducida por contraste a pesar del empleo de medios de contraste no iónicos o de baja osmolaridad ${ }^{34}$ especialmente en pacientes con una disminución en el clearance de creatinina por debajo de $60 \mathrm{ml} / \mathrm{min}$ por $1,73 \mathrm{~m}^{2}$ en quienes aumenta el riesgo de lesión renal ${ }^{35}$.

Si debiéramos elegir una técnica por imagen no invasiva para el diagnóstico de la EAP de MMII, la utilización de la Angio-RM se ubicaría por sobre la Angio-TC en base a la mejor definición de la enfermedad infrapatelar, aunque sin tener diferencia con respecto a la enfermedad del eje aortoilíaco y femoropoplíteo. Obviamente, no resultaría costo-efectivo la utilización adicional de ambas técnicas en un mismo paciente.

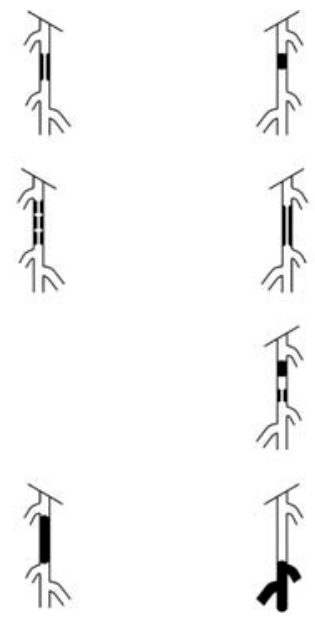

Figura 2. : Inter-Society Consensus for the Management of Peripheral Arterial Disease (TASC). Clasificación de lesiones femoro-poplíteas. AFC: Arteria Femoral Común; AFS: Arteria Femoral Superficial; AP: Arteria Poplítea. Tomado de: Journal of Vascular Surgery 2007 45, S5-S67DOI: (10.1016/j.jvs.2006.12.037

La desventaja de este método hoy en día es la falta de disponibilidad universal y falta de experiencia en la interpretación y procesamiento de las imágenes. Las técnicas anteriormente descritas tienen la desventaja del uso de contraste endovenoso que conlleva riesgo de nefrotoxicidad. En los casos en que los pacientes presentan insuficiencia renal $(\mathrm{ClCr}<60$ $\mathrm{ml} / \mathrm{min}$ ) preferimos reservar la utilización de contraste para el método que proporciona diagnóstico y a su vez posibilidad terapéutica, como es el caso de la angiografía digital.

\section{Conclusiones sobre métodos de diagnóstico No Invasivo:}

- El ITB resulta mandatorio en todo paciente con síntomas o sospecha clínica de EVP. También resulta fundamental en la evaluación previa a la intervención y para el seguimiento.

- La ecografía Doppler es el método universalmente más difundido para el diagnóstico, aunque no resulta suficiente para la planificación terapéutica endovascular. Se resalta también su utilidad para el seguimiento post- intervención.

- La Angio-TC está claramente indicada en la patología del territorio Aorto-Ilíaco y sobre todo cuando la misma se asocia a enfermedad aneurismática, dónde brinda más información anatómica y permite planificar mejor la intervención

- La Angio-TC / Angio-RM pueden brindar información anatómica y guiar una estrategia de revascularización. En isquemia crítica estos métodos podrían aportar información adicional sobre anatomía de partes blandas.

\section{DIAGNÓSTICO INVASIVO}

El diagnóstico invasivo comprende la angiografía digital y el estudio hemodinámico a través del registro de presiones. Permite definir la anatomía arterial y es el patrón de referencia para determinar la sensibilidad y especificidad de las pruebas diagnósticas no invasivas. La evaluación de los gradientes de presión transestenóticos permiten la evaluación de lesiones de dudosa severidad. Claramente la indicación de la angiografía es preterapéutica y no como método diagnóstico de EVP. 


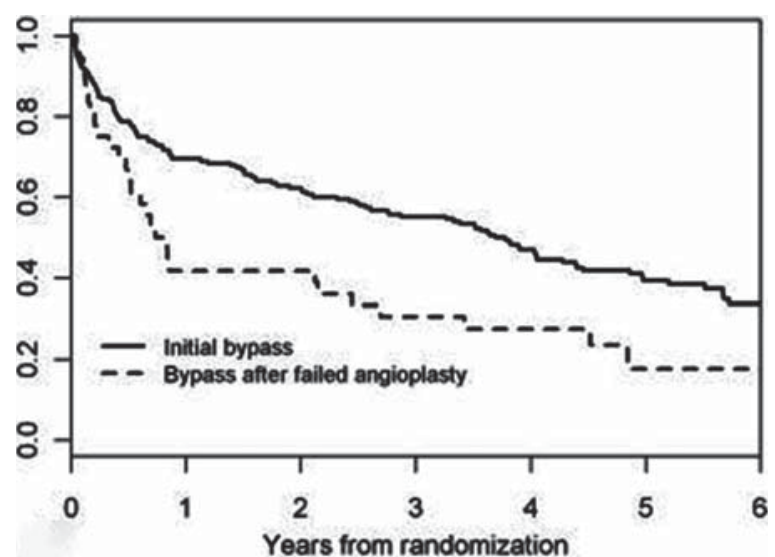

Figura 3. El gráfico demuestra una menor sobrevida libre de amputación para aquellos pacientes que fueran tratados primariamente con angioplastia y esta fallara, con rescate por cirugía, que aquellos en los cuales el método primario de revascularización fuera el bypass.

El abordaje rutinario se realiza a través de la arteria femoral común en forma retrógrada empleando el cruzamiento (crossover) para efectuar la angiografía del miembro contralateral. Constituyen otras alternativas el acceso humeral y radial (con preferencia del lado izquierdo por presentar un recorrido más corto, respecto del derecho), y femoral anterógrado. Cuando se sospecha enfermedad oclusiva infrapatelar no se recomienda el abordaje radial con inyección de contraste desde la aorta dado que la escasa concentración del medio de contraste alcanzada a nivel del pie podría infravalorar los lechos.

Cabe mencionar también, que frente a la oclusión completa de los ejes aortoilíacos, la arteriografía puede eventualmente no permitir valorar el sitio preciso de recanalización por colaterales si esta proviene de segmentos muy superiores como la arteria mamaria interna, por ejemplo. Es esos casos, el complemento de la información mediante Angio-TC o Angio $\mathrm{RM}$ es racional para una mejor planificación terapéutica. La indicación de realizar el diagnóstico invasivo (angiográfico y hemodinámico) es conocer la localización y la extensión de las lesiones en pacientes candidatos a revascularización. Esto permite además planificar la estrategia de revascularización: vía de acceso, características de las placas (longitud, calcificación, bifurcación, etc.), desarrollo de la circulación colateral y compromiso de la misma, velocidad del flujo, estado y características de las arterias distales y del arco plantar.

En la Tabla 5 se exponen las recomendaciones diagnósticas invasivas para el manejo de la EAP de MMII.

\begin{tabular}{|l|c|c|}
\hline \multicolumn{2}{|l|}{ Tabla 5. } \\
\hline $\begin{array}{l}\text { Recomendaciones - Guía de manejo de la EAP de } \\
\text { MMII }\end{array}$ & Clase & $\begin{array}{c}\text { Nivel de evi- } \\
\text { dencia }\end{array}$ \\
\hline $\begin{array}{l}\text { La angiografía digital está recomendada en pacien- } \\
\text { tes con isquemia crítica considerados para revascula- } \\
\text { rización. }\end{array}$ & I & C \\
\hline $\begin{array}{l}\text { La angiografía digital es razonable en pacientes con } \\
\text { claudicación que limita el estilo de vida sin adecuada } \\
\text { respuesta al tratamiento médico y en quienes se pla- } \\
\text { nea una revascularización. }\end{array}$ & ॥a & C \\
\hline $\begin{array}{l}\text { La angiografía invasiva no debe ser considerada en pa- } \\
\text { cientes con EAP de MMIl asintomática. (no recomen- } \\
\text { dada) }\end{array}$ & III & B \\
\hline
\end{tabular}

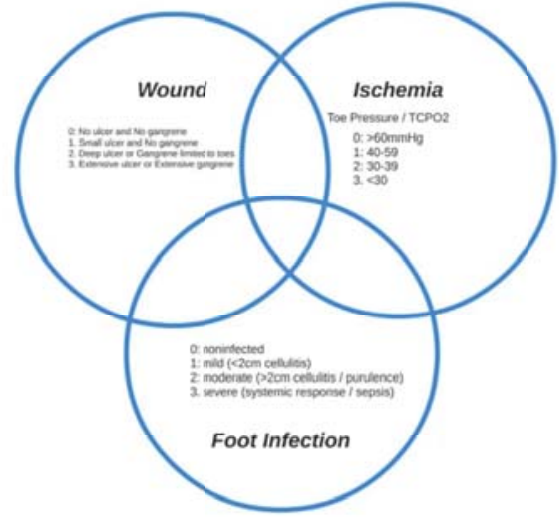

Figura 4. Clasificación WiFi: donde $W$ (wound) se refiere a características de la úlcera, I (ischemia) al grado de isquemia por índice tobillo brazo o presión transcutánea de oxígeno y Fl (foot infection) a la infección en el pie.

\section{ROL DEL TRATAMIENTO MÉDICO EN CONTEXTO DE LA REVASCULARIZACIÓN}

Este apartado se refiere principalmente al tratamiento médico en el contexto de la revascularización. Por tal motivo las recomendaciones y protocolos para ejercicio supervisado, otros vasodilatadores distintos al cilostazol, el empleo de estatinas, prostanoides y nuevos fármacos (vorapaxar, rivaroxaban) que exceden este alcance, no se incluyen en el mismo.

\subsection{Tratamiento antiplaquetario}

El efecto de la antiagregación plaquetaria en pacientes con EVP fue estudiado por un metaanálisis que incluyó 9214 pacientes enrolados en 42 ensayos clínicos de pacientes con CI o revascularización de miembros inferiores ya sea quirúrgica o endovascular. En este estudio se observó una reducción del $23 \%$ en el punto final combinado de muerte, síndrome coronario agudo y $\mathrm{ACV}^{36}$. La mayor reducción de eventos vasculares (32\%) se observó con la dosis de aspirina de 75 a $150 \mathrm{mg}$. Otro metaanálisis que incluyó 5269 pacientes con CI, revascularización o amputación de miembros inferiores mostró 36\% menos riesgo de $\mathrm{ACV}$ no fatal en el grupo de pacientes tratados con aspirina (RR, 0.64; 95\% CI, 0.42-0.99) y una tendencia que no alcanzó la significación estadística a la reducción de muerte e infarto de miocardio. ${ }^{37}$

\begin{tabular}{|l|c|c|}
\hline $\begin{array}{l}\text { Recomendaciones para el tratamiento con } \\
\text { aspirina }\end{array}$ & Clase & $\begin{array}{c}\text { Nivel de } \\
\text { evidencia }\end{array}$ \\
\hline $\begin{array}{l}\text { Se recomienda el tratamiento con } 100 \mathrm{mg} / \text { día de } \\
\text { aspirina en todo paciente con enfermedad vascu- } \\
\text { lar periférica sintomática. }\end{array}$ & । & A \\
\hline
\end{tabular}

\section{Monoterapia con Clopidogrel en EVP}

El estudio CAPRIE comparó la seguridad y eficacia de 75 mg de clopidogrel contra $325 \mathrm{mg}$ de aspirina en una población de pacientes con síndrome coronario o ACV reciente o enfermedad vascular periférica sintomática, mostrando una reducción de $8,7 \%$ del punto final combinado de muerte, infarto y ACV. Esta diferencia se alcanzó debido al efecto en 
la población de pacientes con EAP ya que resultó el subgrupo más beneficiado con $23,8 \%$ de reducción de eventos vasculares. ${ }^{38}$

\begin{tabular}{|l|c|c|}
\hline $\begin{array}{l}\text { Recomendaciones para el tratamiento con } \\
\text { Clopidogrel }\end{array}$ & Clase & $\begin{array}{c}\text { Nivel de } \\
\text { evidencia }\end{array}$ \\
\hline $\begin{array}{l}\text { El tratamiento con clopidogrel } 75 \text { mg día es una al- } \\
\text { ternativa en pacientes que no pueden recibir aspi- } \\
\text { rina. }\end{array}$ & । & $\mathrm{A}$ \\
\hline
\end{tabular}

\section{Doble antiagregación en EVP}

El estudio CHARISMA evaluó la eficacia de la combinación de clopidogrel y aspirina frente aspirina como monoterapia en pacientes de alto riesgo cardiovascular, no encontrando diferencias significativas en cuanto a la reducción de eventos vasculares ${ }^{39}$. Al analizar el subgrupo de pacientes con EVP sintomática tampoco se observó que el agregado de clopidogrel impacte en un menor número de eventos ${ }^{40}$.

\begin{tabular}{|l|c|c|}
\hline $\begin{array}{l}\text { Recomendaciones para el tratamiento con doble terapia } \\
\text { antiagregante }\end{array}$ & Clase & $\begin{array}{c}\text { Nivel de } \\
\text { evidencia }\end{array}$ \\
\hline $\begin{array}{l}\text { La doble antiagregación con aspirina y clopidogrel no } \\
\text { está indicada para el tratamiento crónico de pacientes } \\
\text { con enfermedad vascular periférica que no hayan sido } \\
\text { revascularizados recientemente. (No recomendado) }\end{array}$ & III & B \\
\hline
\end{tabular}

\section{Anticoagulación oral en EVP}

Múltiples estudios randomizados evidenciaron que la anticoagulación oral con inhibidores de la vitamina $\mathrm{K}(\mathrm{ACO})$ en pacientes con EVP no reduce los eventos vasculares y aumenta el riesgo de sangrado mayor e incluso de mortalidad. ${ }^{41,42}$

\begin{tabular}{|l|c|c|}
\hline $\begin{array}{l}\text { Recomendaciones para el tratamiento con anticoagu- } \\
\text { lación oral en EVP }\end{array}$ & Clase & $\begin{array}{c}\text { Nivel de } \\
\text { evidencia }\end{array}$ \\
\hline $\begin{array}{l}\text { La presencia de EVP no constituye una indicación } \\
\text { para el uso de anticoagulación oral. (No recomen- } \\
\text { dado) }\end{array}$ & III & A \\
\hline
\end{tabular}

\subsection{Tratamiento post revascularización endovascular}

Doble antiagregación post revascularización endovascular Existe poca información respecto a la indicación de doble antiagregación luego de un procedimiento de revascularización de miembros inferiores. No obstante, es una práctica habitual el uso de aspirina y clopidogrel luego de un procedimiento endovascular en miembros inferiores ${ }^{43,44}$. El estudio MIRROR randomizó a 80 pacientes sometidos a angioplastia periférica a 6 meses de doble antiagregación con aspirina y clopidogrel contra aspirina y placebo demostrando una reducción en la necesidad de nuevos procedimientos de revascularización. ${ }^{45,46}$ En relación a la dosis de aspirina utilizada, parecería que dosis elevadas no confieren mayor protección anti trombótica pero si aumentan el riesgo de sangrado ${ }^{47}$.

\begin{tabular}{|l|c|c|}
\hline $\begin{array}{l}\text { Recomendaciones para el tratamiento posrevasculariza- } \\
\text { ción endovascular }\end{array}$ & Clase & $\begin{array}{c}\text { Nivel de } \\
\text { evidencia }\end{array}$ \\
\hline $\begin{array}{l}\text { Se recomienda el uso de doble antiagregación con } 100 \\
\text { mg de aspirina y } 75 \mathrm{mg} \text { de clopidogrel por lo menos } \\
\text { durante un mes luego de un procedimiento de revas- } \\
\text { cularización con stent seguido de la administración de } \\
100 \mathrm{mg} \text { de aspirina en forma crónica. }\end{array}$ & I & B \\
\hline
\end{tabular}

\section{Antiagregación post angioplastia con balón con drogas}

No existen estudios que hayan analizado específicamente el esquema de antiagregación en pacientes sometidos a angioplastia con balón liberador de droga. Sin embargo, la gran mayoría de estudios que evaluaron el desempeño de balones con droga en la práctica clínica utilizaron una carga de 300 mg de clopidogrel y $325 \mathrm{mg}$ de aspirina para continuar luego del procedimiento con $75 \mathrm{mg}$ de clopidogrel por un mes y $100 \mathrm{mg}$ de aspirina en forma indefinida $48,49,50,51$

\begin{tabular}{|l|c|c|}
\hline $\begin{array}{l}\text { Recomendaciones para antiagregación post-angioplastia } \\
\text { con balón con drogas (DEB) }\end{array}$ & Clase & $\begin{array}{c}\text { Nivel de } \\
\text { evidencia }\end{array}$ \\
\hline $\begin{array}{l}\text { En pacientes sometidos a angioplastia con balón libe- } \\
\text { rador de droga se recomienda la administración una } \\
\text { carga de } 300 \text { mg de clopidogrel y } 325 \text { mg de aspirina } \\
\text { previa al procedimiento seguido por la administración } \\
\text { de } 75 \text { mg de clopidogrel por } 30 \text { días y } 100 \text { mg de aspi- } \\
\text { rina en forma indefinida. }\end{array}$ & & I \\
\hline
\end{tabular}

Antiagregación post angioplastia con stent liberador de droga (DES)

En relación con los DES tampoco existen estudios que hayan analizado el esquema de antiagregación ideal y la información parecería variar según el sitio anatómico del implante.

En el territorio infrapatelar todos los estudios clínicos utilizan al menos 6 meses de doble antiagregación con $100 \mathrm{mg}$ de aspirina y $75 \mathrm{mg}$ de clopidogrel. ${ }^{52,53,54}$ Mientras que en el territorio femoro poplíteo la indicación de doble antiagregación va de uno a seis meses en los diferentes estudios. ${ }^{55,56,57}$

\begin{tabular}{|c|c|c|}
\hline $\begin{array}{l}\text { Recomendaciones para antiagregación post-angioplastia } \\
\text { con Stent liberador de droga (DES) }\end{array}$ & Clase & $\begin{array}{l}\text { Nivel de } \\
\text { evidencia }\end{array}$ \\
\hline $\begin{array}{l}\text { En pacientes sometidos a angioplastia infrapoplítea } \\
\text { con DES se recomienda una carga de } 300 \mathrm{mg} \text { de clo- } \\
\text { pidogrel y } 325 \mathrm{mg} \text { de aspirina previa al procedimien- } \\
\text { to seguido por la administración de } 75 \mathrm{mg} \text { de clopi- } \\
\text { dogrel entre } 1 \text { y } 6 \text { meses y } 100 \mathrm{mg} \text { de aspirina en for- } \\
\text { ma indefinida. }\end{array}$ & I & B \\
\hline $\begin{array}{l}\text { En pacientes sometidos a angioplastia femoropoplítea } \\
\text { con DES se recomienda una carga de } 300 \mathrm{mg} \text { de clo- } \\
\text { pidogrel y } 325 \mathrm{mg} \text { de aspirina previa al procedimien- } \\
\text { to seguido por la administración de } 75 \mathrm{mg} \text { de clopi- } \\
\text { dogrel entre } 1 \text { mes y } 6 \text { meses y } 100 \mathrm{mg} \text { de aspirina en } \\
\text { forma indefinida. }\end{array}$ & 1 & $C$ \\
\hline
\end{tabular}

\section{Anticoagulación oral luego de revascularización endovascular}

Dos estudios aleatorizados evaluaron el uso de anticoagulación oral con inhibidores de vitamina $\mathrm{K}$ luego de un procedimiento de revascularización endovascular. Ninguno de los estudios logró demostrar una mejoría en la permeabilidad del vaso, al tiempo que se registró un aumento de sangrado ${ }^{58,59}$.

\begin{tabular}{|l|c|c|}
\hline $\begin{array}{l}\text { Recomendaciones para anticoagulación oral luego de re- } \\
\text { vascularización endovascular }\end{array}$ & Clase & $\begin{array}{c}\text { Nivel de } \\
\text { evidencia }\end{array}$ \\
\hline $\begin{array}{l}\text { La realización de un procedimiento de revasculariza- } \\
\text { ción endovascular no constituye una indicación de an- } \\
\text { ticoagulación oral con inhibidores de vitamina K. (No } \\
\text { Recomendada) }\end{array}$ & III & A \\
\hline
\end{tabular}

\section{Cilostazol post revascularización endovascular}

Dos ensayos clínicos no ciegos realizados en Japón, randomizaron 80 y 200 pacientes respectivamente, a recibir aspirina $100 \mathrm{mg} /$ día o aspirina y Cilostazol 100 mg cada 
12 hs. Ambos estudios mostraron una reducción significativa de la restenosis y necesidad de nuevos procedimientos de revascularización ${ }^{60,61}$. Si bien estos resultados fueron promisorios, aún no fueron corroborados en estudios doble ciego en poblaciones mayores, fuera de Asia, ni en pacientes tratados con doble antiagregación.

\begin{tabular}{|l|c|c|}
\hline $\begin{array}{l}\text { Recomendaciones para uso de Cilostazol luego de revas- } \\
\text { cularización endovascular }\end{array}$ & Clase & $\begin{array}{c}\text { Nivel de } \\
\text { evidencia }\end{array}$ \\
\hline $\begin{array}{l}\text { El uso de cilostazol podría ser considerado luego de un } \\
\text { procedimiento endovascular a fin de reducir la tasa de } \\
\text { restenosis. }\end{array}$ & Il b & B \\
\hline
\end{tabular}

Tratamiento post revascularización quirúrgica: Antiagregación en bypass periférico

Un metaanálisis de 16 estudios clínicos evaluó la efectividad de la antiagregación con aspirina o aspirina y dipiridamol para mantener la permeabilidad de un by-pass periférico. Los pacientes anti agregados mostraron una mayor permeabilidad al año del conducto de revascularización utilizado, siendo el subgrupo de los pacientes tratados con by-pass protésico los más beneficiados del tratamiento antiagregante. ${ }^{62}$

\begin{tabular}{|l|c|c|}
\hline $\begin{array}{l}\text { Recomendaciones para antiagregación en bypass peri- } \\
\text { férico }\end{array}$ & Clase & $\begin{array}{c}\text { Nivel de } \\
\text { evidencia }\end{array}$ \\
\hline $\begin{array}{l}\text { Todo paciente tratado con un bypass periférico debe } \\
\text { recibir aspirina } 100 \mathrm{mg} / \text { día a fin de prevenir la oclu- } \\
\text { sión del mismo. Se reserva el uso de clopidogrel } 75 \\
\text { mg/día para pacientes con contraindicación al uso de } \\
\text { aspirina. }\end{array}$ & I & A \\
\hline
\end{tabular}

\section{Anticoagulación en bypass periférico}

El estudio BOA aleatorizó 2690 pacientes con bypass periférico a recibir anticoagulación oral con un RIN de 3 a 4.5 o aspirina $80 \mathrm{mg} /$ día, no observándose diferencias en la permeabilidad primaria del bypass. Sin embargo, los subgrupos de pacientes con conductos venosos tuvieron una mayor permeabilidad alejada a expensas de un mayor riesgo de sangrado ${ }^{63}$. Otro estudio de 665 pacientes con bypass femoropoplíteo randomizados a recibir aspirina $325 \mathrm{mg} /$ día o aspirina y warfarina (RIN 1,4 a 2,8), no pudo demostrar diferencias en cuanto a la efectividad, pero sí un mayor riesgo de sangrado en el grupo de pacientes con doble terapia.

Algo similar fue observado en un estudio menor de 56 pacientes con bypass periférico con alto riesgo de oclusión, randomizados a recibir $325 \mathrm{mg} / \mathrm{día}$ de aspirina o similar dosis de aspirina y warfarina (RIN 2 a 3). A 3 años de seguimiento la oclusión del bypass o necesidad de amputación fue menor entre los pacientes tratados con aspirina y anticoagulación, pero una vez más a expensas de un mayor riesgo de sangrado.

\begin{tabular}{|l|c|c|}
\hline $\begin{array}{l}\text { Recomendaciones para anticoagulación en By-Pass peri- } \\
\text { férico }\end{array}$ & Clase & $\begin{array}{c}\text { Nivel de } \\
\text { evidencia }\end{array}$ \\
\hline $\begin{array}{l}\text { El tratamiento anticoagulante con antagonistas de la } \\
\text { vitamina K puede ser considerado en pacientes con un } \\
\text { bypass infrainguinal especialmente en casos de con- } \\
\text { ductos venosos con alto riesgo de oclusión y en pa- } \\
\text { cientes con bajo riesgo de sangrado. }\end{array}$ & Ilb & B \\
\hline
\end{tabular}

\section{ANGIOPLASTIA EN TERRITORIO AORTOILÍACO}

\subsection{Consideraciones generales de la ATP en terri- torio Aorto-Ilíaco}

Históricamente, la cirugía de by-pass aorto-bi-femoral o bi-ilíaco ha sido el tratamiento de revascularización de elección para la patología del sector aorto-ilíaco con una alta tasa de permeabilidad alejada del 72-90\% a 10 años, demostrada en estudios observacionales ${ }^{64,65,66,67}$. A pesar de esto, el crecimiento de la experiencia médica en los procedimientos endovasculares asociado al continuo avance de la tecnología y del equipamiento para las intervenciones percutáneas genera un permanente desafío a éste paradigma, como se ve reflejado en un reporte con datos de la "Nationwide Inpatient Sample" (NIS) ${ }^{67}$.

Hasta el momento no se han realizados estudios clínicos randomizados que comparen ambas estrategias terapéuticas, por lo que los datos clínicos y resultados se obtienen de estudios observacionales, lo que puede generar un considerable riesgo de sesgo y hace difícil la recomendación de uno u otro método.

Si bien la permeabilidad primaria alejada de la angioplastia (60-80\% a los 5 años) es inferior a la quirúrgica, la permeabilidad secundaria alcanza el 80-98\%, equivalente a la permeabilidad primaria alejada de la cirugía ${ }^{64,68,69,70,71}$. Por otro lado, el tratamiento endovascular de la enfermedad aorto-ilíaca fue asociado con una baja frecuencia de complicaciones, menor estadía hospitalaria y menor costo en comparación con cirugía según datos obtenidos del NIS desde 2004 hasta $2007^{72}$. En el mismo sentido, un metaanálisis que reunió datos de estudios observacionales de pacientes con enfermedad Aorto-ilíaca tratados con cirugía o angioplastia mostró superior permeabilidad alejada con la estrategia quirúrgica, pero ésta se relacionó con una mayor estadía hospitalaria, mayor incidencia de complicaciones y mayor mortalidad ${ }^{73}$.

Una alternativa terapéutica en los pacientes con enfermedad aorto-ilíaca, principalmente cuando se trata de lesiones difusas u obstrucciones totales son los procedimientos híbridos que combinan el tratamiento endovascular con la cirugía abierta. Estos son necesarios en aproximadamente el 24\% de los pacientes TASC C/D ${ }^{74}$. Los procedimientos híbridos más habituales son endarterectomía de la arteria femoral común con angioplastia con stent en ilíaca ipsilateral para enfermedad difusa que se extiende desde las arterias ilíacas y compromete la femoral común o angioplastia con stent de arteria ilíaca dadora y by-pass femoro-femoral cruzado en estenosis severa de una arteria ilíaca con obstrucción total larga que compromete iliaca común y externa contralateral. Así, el tratamiento endovascular, se impone sobre todo en contexto de riesgo de la intervención quirúrgica y los buenos resultados inmediatos y a largo plazo que presenta la angioplastia. Para lesiones TASC A-C la indicación endovascular representa el tratamiento a seguir. Las lesiones TASC $\mathrm{D}$, son pasibles de tratamiento endovascular, sin embargo, requiere gran experiencia del centro y la indicación debe darse atendiendo comorbilidades del paciente y en el marco de un equipo vascular.

En el tratamiento de lesiones complejas, se sugiere el tratamiento por etapas, con relación a la enfermedad residual, evitando procedimientos extensos y preservando al paciente (cantidad de contraste, función renal, volumen infundido, riesgo de embolia, etc.) 
En cuanto al tratamiento endovascular existe un solo estudio clínico randomizado, que comparó angioplastia con implante de stent provisional cuando el gradiente de presión persiste mayor a $10 \mathrm{~mm} / \mathrm{Hg}$ luego de angioplastia sola versus implante de stent primario. Este estudio incluyó 279 pacientes y no mostró diferencias significativas en mejoría clínica ni en la tasa de permeabilidad a 1 año ${ }^{75}$. No obstante, estos resultados, un metaanálisis publicado por Bosch incluyendo 2116 pacientes demostró una reducción del riesgo relativo de oclusión del 39\% con el implante primario del stent, comparado con angioplastia sola ${ }^{76}$.

\begin{tabular}{|l|c|c|}
\hline $\begin{array}{l}\text { Recomendaciones - Angioplastia en territorio aor- } \\
\text { to-llíaco }\end{array}$ & Clase & $\begin{array}{c}\text { Nivel de } \\
\text { evidencia }\end{array}$ \\
\hline $\begin{array}{l}\text { El tratamiento endovascular se recomienda como } \\
\text { primera estrategia en todas las lesiones aorto-ilía- } \\
\text { cas TASC A-C. }\end{array}$ & I & B \\
\hline $\begin{array}{l}\text { En lesiones TASC D se puede intentar un abordaje } \\
\text { endovascular en pacientes con graves comorbilida- } \\
\text { des y en un equipo con experiencia }\end{array}$ & ॥la & C \\
\hline $\begin{array}{l}\text { Está recomendada la utilización de stents en forma } \\
\text { primaria para la gran mayoría de las lesiones aor- } \\
\text { to-ilíacas pudiéndose optar por angioplastia con } \\
\text { stent provisional para lesiones focales de baja com- } \\
\text { plejidad. }\end{array}$ & ॥la & B \\
\hline
\end{tabular}

\subsection{Tipo de stent: Balón Expandible vs. Autoexpandible}

En cuanto al tipo de stent, expandible por balón (EB) o auto-expandible (AE), no han sido adecuadamente evaluados en estudios comparativos. A pesar de esto ciertas características de las lesiones y localización de las mismas pueden favorecer uno u otro diseño. La opción de utilizar stent balón o auto expandibles está basada en la necesidad de la lesión y su localización (fuerza radial, calcificación, curvatura, extensión de la lesión, necesidad de máxima precisión, región ilíaca externa, etc.). Es de vital importancia el reconocimiento y el tratamiento de la enfermedad en este segmento, ya que permite en algunos casos el abordaje a segmentos distales, así como contribuye al éxito del resto de las intervenciones como al salvataje del miembro. Recomendamos stent balón expandible para: lesiones de Aorta; ostium de Ilíacas primitivas; para la realización de kissing stent y para lesiones marcadamente calcificadas, dado su mayor fuerza radial y precisión en el implante. Por otro lado, las características de los stents autoexpandibles los hacen ideales para anatomías tortuosas, lesiones largas que comprometan Ilíaca Primitiva y Externa, con discrepancia de diámetros entre ambas.

Algunos estudios observacionales y metaanálisis avalan el uso de los stents cubiertos principalmente en lesiones complejas TASC B/C 77,78 . Sin embargo, en un estudio randomizado que incluyó 125 pacientes (168 lesiones) no hubo diferencias estadísticamente significativas en el punto final primario de permeabilidad a los 18 meses entre ambos grupos, en el análisis de subgrupos se observó una mayor permeabilidad a mediano plazo con stents cubiertos en lesiones TASC $\mathrm{C} / \mathrm{D}^{79}$. A su vez, un estudio descriptivo de 162 pacientes (254 procedimientos), observó mayor permeabilidad con los stent convencionales y no encontró diferencias según la clasificación TASC II ${ }^{80}$. Son necesarios estudios clínicos randomizados con un número suficiente de pacientes, para evaluar si los stents cubiertos son más eficaces que los desnudos, por

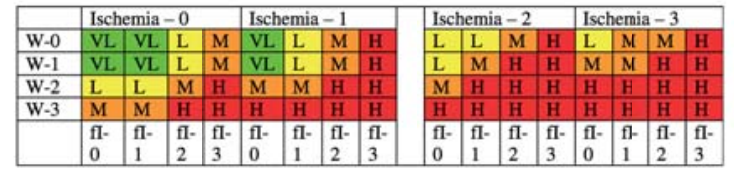

Figura 5. Riesgo estimado de amputación al año. En donde VL (very low), L (low), $\mathrm{M}$ (moderate) y $\mathrm{H}$ (high) son muy bajos, bajos, moderados y alto riesgo para amputación teniendo en cuenta las características y puntajes de Fl (foot infection, infección del pie), I (ischemia, isquemia) y W (wound, herida).

lo que solo los recomendamos en casos excepcionales, en los que determinadas características anatómicas los justifiquen. Por último, consideramos que la clasificación anatómica de la TASC II (Figura 1) continúa siendo de gran utilidad para guiar la estrategia terapéutica, siendo en las lesiones tipo A y B de primera elección el tratamiento endovascular y en las tipo C y D se deberán tener en cuenta además, las comorbilidades y el riesgo cardiovascular del paciente como así también la experiencia y la disponibilidad de materiales del centro para decidir la mejor estrategia terapéutica.

\section{ANGIOPLASTIA EN TERRITORIO FEMOROPOPLÍTEO}

\subsection{Consideraciones generales}

La enfermedad aterosclerótica en el sector arterial femoropoplíteo (FP) muestra características muy diferenciadas respecto a otros territorios. Por su longitud y tortuosidad, ocasiona un patrón hemodinámico del flujo alterado con bajo shear stress a nivel del hiato aductor. Esto favorece el desarrollo de placas ateroscleróticas, sumado a las fuerzas mecánicas que actúan sobre la arteria femoral superficial, como la compresión y extensión axial, compresión radial, elongación y torsión. De por sí, esto conforma un escenario muy hostil para las intervenciones endovasculares, a lo que se agrega un elevado volumen de placa (carga de placa) y alto grado de calcificación, especialmente en pacientes diabéticos y con insuficiencia renal. Uno de los principales problemas de la revascularización en este territorio es la alta prevalencia de enfermedad difusa.

No obstante, la baja morbimortalidad de las técnicas EV como ATP con balón y stent, hacen de esta la modalidad de tratamiento preferida en este segmento.

Adicionalmente la restenosis parecería ser más agresiva aquí que en comparación con otros territorios vasculares, como el coronario o el Ilíaco.

La selección del tratamiento más adecuado para territorio FP debe ser evaluada caso por caso y teniendo en cuenta la anatomía, las comorbilidades, la experiencia y la disponibilidad local de recursos dado que no hay recomendaciones firmes de guías de práctica clínica.

Si bien la clasificación TASC es en la actualidad bastante extemporánea debido a la dinámica que ha tenido la evolución de la tecnología desde su publicación, se la sigue mencionando y por esa razón la consideramos aquí, también a título didáctico.

La actual disponibilidad de dispositivos como: balones con drogas; stents metálicos de nitinol; stents liberadores de droga; stents cubiertos y otras tecnologías como la aterectomía aumentan las alternativas terapéuticas para el tratamiento de la enfermedad en este territorio.

\subsection{Tratamiento mediante Balón Convencional}

Una característica de las lesiones FP es que la permeabilidad subóptima se traduce en elevada restenosis. Cuanto más lar- 


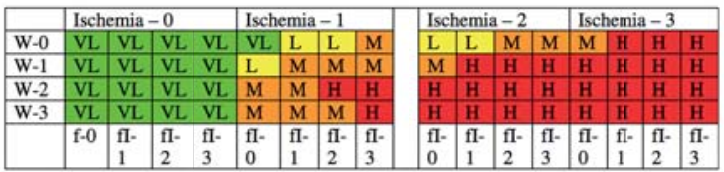

Figura 6. Necesidad de revascularización de acuerdo con la clasificación WiFi. Por ejemplo, una lesión WiFi con una alto índice de Isquemia (13) tiene un beneficio grande con la revascularización. fi (foot infection, infección del pie), I (ischemia, isquemia) y W (wound, herida).

ga la lesión, más probable es que se produzcan disecciones severas, retroceso elástico y desplazamiento de placa.

La tasa de éxito técnico en territorio FP es 95 y $85 \%$ para estenosis y oclusión, respectivamente. Los dispositivos dedicados para reentrar a la luz verdadera desde trayecto sub-intimal han mejorado el éxito técnico aún en oclusiones muy largas y calcificadas del territorio FP.

La angioplastia con balón convencional es el método de elección para lesiones cortas, concéntricas o poco calcificadas, pero tiene alta tasa de restenosis, superior a $30 \%$.

El tratamiento endovascular con balón es un procedimiento seguro y efectivo en lesiones con complejidad TASC A-C, (Figura 2), mientras que para los pacientes portadores enfermedad compatible con TASC D, la intervención quirúrgica es una buena opción.

Debemos considerar en la decisión de tratamiento el riesgo isquémico cardiaco del paciente, así como sus comorbilidades. En las lesiones complejas la severa calcificación también juega un rol limitante en la angioplastia, ya que a pesar de un buen resultado inmediato la durabilidad no es aceptable para la cicatrización de la lesión trófica cuando esta se presenta. En estos casos, una estrategia híbrida es una alternativa.

La tecnología ha evolucionado, sin embargo, es necesario aclarar que la mayoría de los dispositivos se encuentran estudiados en contexto de pacientes claudicantes y en forma escasa en isquemia crítica. La angioplastia con balón ha certificado su utilidad a mediano y largo plazo, con una alta eficacia en el salvataje del miembro (80\%) en múltiples estudios ${ }^{81-82}$. Sin embargo, la permeabilidad primaria tanto en lesiones severas (43\%) como en oclusiones totales $(30 \%)$ a mediano y largo plazo es pobre, sujeto a múltiples reintervenciones ${ }^{83}$.

\begin{tabular}{|l|c|c|}
\hline $\begin{array}{l}\text { Recomendaciones para angioplastia en territorio femo- } \\
\text { ropoplíteo con balón convencional }\end{array}$ & Clase & $\begin{array}{c}\text { Nivel de } \\
\text { evidencia }\end{array}$ \\
\hline $\begin{array}{l}\text { Se recomienda el tratamiento de estenosis focales } \\
\text { mediante angioplastia con balón y stent provisional. }\end{array}$ & I & C \\
\hline
\end{tabular}

\subsection{Tratamiento mediante stent convencional}

En cuanto a la colocación de stent, hay consenso general de que deben implantarse ante falla aguda de ATP con balón debida a trombosis, disección con compromiso de flujo o estenosis residual significativa. Como ya se mencionara, la arteria femoral superficial es sometida a distintas deformaciones mecánicas en múltiples direcciones durante el movimiento de la pierna. Esto explica porque los stents montados sobre balón tienen menor capacidad para adaptarse a las fuerzas mecánicas que actúan sobre el eje femoropoplíteo y por esa razón no se utilizan frecuentemente.

En el territorio FP, los stents de nitinol autoexpandibles, sin ninguna duda han cambiado las perspectivas de tratamiento ${ }^{84-85}$. Son muy flexibles y son mejores que los stent expandibles por balón. La estrategia del pasado era implantarlos sólo en casos de falla de ATP con balón o recurrencia. Sin embargo, ahora hay estudios randomizados que muestran que el stent de nitinol primario es el tratamiento de primera línea debido a su permeabilidad a mediano plazo. La restenosis a 1 y 2 años es 20 y $30 \%$ menor que con balón ${ }^{86-87}$.

En caso de necesitar un stent en segmentos curvos de las arterias FP, es de mucha utilidad hacer una angiografía en flexión antes de la colocación para observar el comportamiento biomecánico del segmento a tratar y decidir el implante de acuerdo con esto. El diámetro de un stent de nitinol AE debe ser $10 \%$ mayor al diámetro de referencia del vaso.

Se recomienda el empleo de stents diseñados específicamente para el segmento femoropoplíteo en segmentos largos o de flexión, para disminuir la posibilidad de complicaciones alejadas como la fractura del dispositivo ${ }^{88,89}$.

\begin{tabular}{|l|c|c|}
\hline $\begin{array}{l}\text { Angioplastia en Territorio femoropoplíteo mediante } \\
\text { stent }\end{array}$ & Clase & $\begin{array}{c}\text { Nivel de } \\
\text { evidencia }\end{array}$ \\
\hline $\begin{array}{l}\text { Se recomienda el empleo de stents autoexpandibles } \\
\text { de diseño específico para lesiones largas y/o calcifi- } \\
\text { cadas o como stent provisional en lesiones tratadas } \\
\text { con balón. }\end{array}$ & Ila & B \\
\hline
\end{tabular}

\subsection{Tratamiento mediante stent liberador de dro- ga (DES)}

La utilización de este stent autoexpandible DES, demostró resultados de permeabilidad a 2 años mayores del $80 \%$. Sin embargo, todavía los resultados no son extrapolables a poblaciones de mayor complejidad como la de isquemia crítica, ya que se incluyeron en menos del $9 \%$ a esta población ${ }^{90,91}$.

La eficacia de DES en arteria FS fue demostrada con un stent liberador de paclitaxel en el estudio original de permeabilidad al año como en su seguimiento a 5 años, para lesiones de longitud menor a $14 \mathrm{~cm}$. Fue comparado con balón solo en una primera randomización y con BMS de nitinol en una segunda randomización. En ambos casos la permeabilidad y ausencia de nueva revascularización fueron superiores con el DES $^{92}$.

\begin{tabular}{|l|c|c|}
\hline $\begin{array}{l}\text { Recomendaciones para angioplastia en territorio fe- } \\
\text { moro-poplíteo mediante stent liberador de droga }\end{array}$ & Clase & $\begin{array}{c}\text { Nivel de } \\
\text { evidencia }\end{array}$ \\
\hline $\begin{array}{l}\text { Se recomienda el empleo de DES autoexpandible } \\
\text { para el tratamiento de estenosis u oclusiones de } \\
\text { novo largas o reestenosis posangioplastia con ba- } \\
\text { lón. }\end{array}$ & Ila & C \\
\hline
\end{tabular}

\subsection{Tratamiento mediante Angioplastia con Balón Liberador de Droga (DEB)}

Las limitaciones de los stents (baja permeabilidad, zonas de flexión, fractura, doble antiagregación, trombosis) han promovido una nueva estrategia de tratamiento en el segmento FP como el balón liberador de droga (DEB). El DEB ha sido diseñado para llevar y administrar droga en la pared arterial con el objetivo de reducir las chances de restenosis y la necesidad de nuevas re-intervenciones.

Los distintos DEB en el mercado difieren respecto de la dosis de droga (paclitaxel), el excipiente molecular responsable de cargar la droga y facilitar su transferencia hacia la pared arterial, el material del balón y la tecnología empleada para el desarrollo del balón y el revestimiento de la droga. Por tal motivo los resultados de los trabajos randomizados con cada balón con droga no pueden ser generalizados.

Un metaanálisis actualizado de trabajos clínicos randomizados publicado en la revista JACC Cardiovascular Interv. en el 2016 mostró que, comparado con el balón convencional, el 
DEB reduce significativamente la incidencia de restenosis y la necesidad de revascularización de la lesión culpable, mejorando así la permeabilidad primaria ${ }^{93}$.

Dos trabajos randomizados (Acoart I trial y LEVANT II) compararon los resultados de la angioplastia con DEB versus balón convencional en lesiones "de novo" en el sector arterial FP. Encontraron una fuerte evidencia a favor del balón con droga, respecto a una mejor permeabilidad primaria, menor reestenosis y menor necesidad de revascularización de la lesión responsable ${ }^{94-95}$. Estos resultados del DEB se mantienen a dos años de seguimiento. El estudio THUNDER, mostró resultados a 5 años a favor del DEB respecto a los mismos parámetros ${ }^{96}$. La angioplastia con balón con droga como terapéutica de las lesiones "de novo" TASC II A y B ha demostrado muy buenos resultados a mediano plazo en términos de restenosis, permeabilidad primaria y necesidad de revascularización de la lesión culpable en comparación con el balón convencional, por lo que es la estrategia actualmente recomendada para el tratamiento de estas lesiones. Se necesitan estudios que comparen el balón con droga con otras tecnologías, como el stent con droga y las técnicas de reducción del volumen de la placa (aterectomía y modificación de placa), en el tratamiento de las lesiones "de novo".

\begin{tabular}{|l|c|c|}
\hline $\begin{array}{l}\text { Recomendaciones para angioplastia en territorio femoro- } \\
\text { poplíteo mediante balón liberador de droga }\end{array}$ & Clase & $\begin{array}{c}\text { Nivel de } \\
\text { evidencia }\end{array}$ \\
\hline $\begin{array}{l}\text { Se recomienda el empleo de DEB para tratamiento de } \\
\text { lesiones estenóticas mayores a } 5 \mathrm{~cm} .\end{array}$ & Ila & B \\
\hline $\begin{array}{l}\text { Se recomienda el empleo de DEB post-dilatación con } \\
\text { balón para tratamiento de oclusiones cortas. }\end{array}$ & Ila & C \\
\hline $\begin{array}{l}\text { Se recomienda el empleo de DEB para tratamiento de } \\
\text { la restenosis intrastent }\end{array}$ & Ila & B \\
\hline
\end{tabular}

\subsection{Tratamiento de lesiones complejas}

El rol del tratamiento quirúrgico no puede ser soslayado en este tipo de lesiones. No obstante, en pacientes de elevado riesgo quirúrgico, comorbilidades o anatomía no favorable el tratamiento endovascular puede considerarse.

El empleo de stents autoexpandibles en lesiones largas, muy calcificadas u oclusiones totales largas (TASC C y D) en este territorio demostró resultados alejados poco promisorios, debido a una elevada tasa de restenosis, fracturas y deformación de los dispositivos ${ }^{97}$.

Por otra parte, la mayor evidencia de la eficacia del balón con droga (DEB) como tratamiento de las lesiones de novo TASC C y D proviene de estudios multicéntricos no aleatorizados, registros y de un conjunto de análisis con nivel de evidencia $\mathrm{B}$, más que de estudios randomizados multicéntricos. Al tratar lesiones largas, calcificadas y oclusiones totales con el balón con droga, las limitaciones son el retroceso elástico; la placa residual; las disecciones, limitantes o no de flujo, y la insuficiente o imposible dilatación de lesiones muy calcificadas. En lesiones con calcificación endoluminal circunferencial, suele estar muy limitado el acceso de la droga a la túnica media y es frecuente la necesidad de utilizar un stent de rescate. Un concepto importante en el tratamiento con balón con droga, que el grado mayor de estenosis residual es aceptable, en comparación con el buscado con el balón convencional, ya que no compromete los resultados en términos de permeabilidad primaria. Esto estaría relacionado a que el Paclitaxel induce una regresión de la placa residual. También un estudio retrospectivo de Tepe et al. observó que el grado de estenosis residual post angioplastia con balón con droga no tenía influencia estadísticamente significativa en la pérdida tardía del lumen. Este estudio también estableció que el alto grado de calcificación de la lesión es un predictor significativamente negativo de pérdida tardía del lumen luego de la angioplastia con balón con droga, especialmente la calcificación circunferencial ${ }^{98-99}$.

Respecto de la angioplastia subintimal, en el estudio DEBATE-SFA que comparó la angioplastia con balón con droga más stent metálico versus angioplastia con balón convencional más stent metálico en el tratamiento de lesiones de novo TASC C y D, se observó una menor tasa de restenosis al año en la rama balón con droga-stent metálico, especialmente en el grupo de recanalización subintimal (0\%) vs $47,1 \%$, para el balón convencional $(\mathrm{p}<0,01)$

El registro LUTONIX GLOBAL analizó lesiones entre $140-500 \mathrm{~mm}$ de longitud, resultando que el 42,1\% eran oclusiones totales. La permeabilidad primaria de la lesión culpable fue similar entre las lesiones largas comparado con la totalidad de las lesiones (93\% vs 93,6\%). Sin embargo, la tasa de reintervención por embolia distal o trombosis, fue ligeramente superior en las lesiones largas (2,3\% de embolia distal y trombosis) versus $0,6 \%$ y $1,3 \%$ en todas las lesiones. La necesidad de stent provisional ocurrió en el 25,2\% de los casos ${ }^{100}$

Un grupo de lesiones largas fueron analizadas en el registro GLOBAL IN.PACT, 157 lesiones con una longitud de $26,40+/-8,61 \mathrm{~cm}$ de las cuales el $60,4 \%$ eran oclusiones totales, observándose para el empleo del DEB una permeabilidad primaria a 360 días del $91 \%$ y a 390 días del $80,7 \%$ con una necesidad de stent de rescate del $40,4 \%{ }^{101}$.

Podemos decir entonces que el empleo del DEB como tratamiento de las lesiones de novo TASC C y D presenta como limitante una alta tasa de estenosis residual y necesidad de stent provisional entre un 10 y $40 \%$. Sin embargo, la estenosis residual sin compromiso de flujo es bien aceptada y no interfiere en los resultados clínicos en el seguimiento.

\begin{tabular}{|l|c|c|}
\hline $\begin{array}{l}\text { Recomendaciones en el tratamiento de lesiones comple- } \\
\text { jas Cy D }\end{array}$ & Clase & $\begin{array}{c}\text { Nivel de } \\
\text { evidencia }\end{array}$ \\
\hline $\begin{array}{l}\text { El tratamiento quirúrgico se recomienda para las lesio- } \\
\text { nes más complejas (TASC D) }\end{array}$ & $\mathrm{I}$ & $\mathrm{A}$ \\
\hline $\begin{array}{l}\text { Para el tratamiento endovascular de oclusiones tota- } \\
\text { les largas se recomienda el uso de DES }\end{array}$ & $\mathrm{Ilb}$ & $\mathrm{B}$ \\
\hline $\begin{array}{l}\text { El uso de DEB puede ser considerado como alternativa } \\
\text { para este tipo de lesiones }\end{array}$ & $\mathrm{Ilb}$ & $\mathrm{C}$ \\
\hline
\end{tabular}

\subsection{Tratamiento de la Restenosis Intrastent del sector Femoropoplíteo}

Las lesiones por restenosis intrastent son muy complejas y difieren significativamente de las lesiones ateroscleróticas. La lesión reestenótica es heterogénea y está constituida fundamentalmente por colágeno, células musculares espumosas y alto contenido en agua. Una lámina íntima interna, formada por un denso tejido de células musculares espumosas y una lámina íntima externa, que contiene Colágeno representa el mayor volumen de la lesión reestenótica.

La luz obtenida durante el tratamiento de la angioplastia de la restenosis intrastent con el balón consiste en tres mecanismos:

Compresión del tejido por el balón, que exprime hacia afuera el contenido de agua de la hiperplasia neointimal. 
La extrusión del tejido reestenótico a través de la estructura del stent.

Una expansión adicional del stent, y esta última es la responsable del 56\% del lumen ganado.

En un análisis volumétrico realizado con IVUS durante el tratamiento de la restenosis intrastent con balón, se observó que inmediatamente después de la angioplastia el volumen de tejido intrastent se reduce en un $50 \%$ y 30 minutos después aumenta un $32 \%^{102}$.

Estudios recientes han demostrado un claro beneficio del balón con droga versus el balón convencional en el tratamiento de la restenosis intrastent en el sector FP, aunque los resultados parecen ser menos favorables que en las lesiones de novo ${ }^{103,104,105}$

La tasa de restenosis intrastent, en varios trabajos randomizados con lesiones de longitud media $<10 \mathrm{~cm}$, fue en promedio del 20\% al año ${ }^{106,107}$ En la práctica diaria es habitual el tratamiento de lesiones significativamente largas, en las cuales es dable esperar tasas de restenosis elevadas.

Si bien hay una tendencia a reducir el uso de stent primario en favor de usar balón con droga, la presencia de disección, retroceso elástico o una lesión residual significativa es de alrededor del $40 \%$ en lesiones largas. Por lo tanto, el problema de la restenosis intrastent afecta significativamente los resultados a mediano y largo plazo del sector arterial FP 108

El primer estudio que evaluó los resultados del DEB en el tratamiento de la restenosis intrastent $\mathrm{FP}$, fue un registro realizado por Stabile y col, en el que se observó una permeabilidad primaria del $92,1 \%$ en el primer año, independientemente de la longitud de la lesión, observándose a los dos años una reducción de la permeabilidad primaria al 70,3\% especialmente en lesiones más largas ${ }^{106}$.

\section{Actualmente hay tres opciones terapéuticas aprobadas por} FDA para el tratamiento de RIS:

Un stent cubierto auto expandible ha demostrado en el estudio RELINE Trial mayor permeabilidad al año y menor revascularización de lesión blanco (RLB) comparado con balón solo, para lesiones reestenóticas largas de más de $15 \mathrm{~cm}$ de longitud ${ }^{109}$.

La aterectomía con láser no se realiza de manera práctica en nuestro medio. Comparado con balón solo en el estudio EXCITE ISR Trial ha demostrado mayor permeabilidad y menor RLB a 6 meses, aunque las tasas de permeabilidad son bajas ${ }^{110,111,112}$.

El balón liberador de paclitaxel demostró, en el estudio IN.PACT Global en pacientes con RIS, la eficacia y seguridad del DEB comparado con balón solo. La permeabilidad lograda fue la mejor conseguida hasta la fecha entre las distintas modalidades terapéuticas y la tasa de trombosis al año fue de $0.8 \% .^{113}$

\begin{tabular}{|l|c|c|}
\hline $\begin{array}{l}\text { Recomendaciones para el tratamiento de la reestenosis } \\
\text { intrastent en territorio femoropoplíteo }\end{array}$ & Clase & $\begin{array}{c}\text { Nivel de } \\
\text { evidencia }\end{array}$ \\
\hline $\begin{array}{l}\text { Se recomienda para el tratamiento de la restenosis in- } \\
\text { trastent el empleo de balón liberador de drogas }\end{array}$ & Ila & B \\
\hline $\begin{array}{l}\text { El empleo de stent cubierto de nitinol autoexpandible } \\
\text { podría considerarse como alternativa }\end{array}$ & Ila & B \\
\hline $\begin{array}{l}\text { El empleo de Balón sólo sigue siendo una alternativa } \\
\text { en el tratamiento de reestenosis focales. }\end{array}$ & Ila & B \\
\hline $\begin{array}{l}\text { La utilización de stents autoexpandibles no estaría re- } \\
\text { comendada }\end{array}$ & III & C \\
\hline
\end{tabular}

\section{ANGIOPLASTIA EN TERRITORIO INFRAPOPLÍTEO}

\subsection{Introducción}

En los pacientes que indicamos este tipo de revascularización hay una multiplicidad de factores involucrados. Es una población con alto predominio de DBT e IR crónica, que consulta por isquemia crítica, con trastornos tróficos e infecciones, por lo que es habitual que requieran un abordaje multidisciplinario. Suele haber obstrucciones a varios niveles con compromiso habitual a nivel femoral. Las lesiones en las arterias infrapatelares son complejas con alta frecuencia de calcificaciones, lesiones en tándem y oclusiones.

\subsection{Indicación de revascularización}

Los objetivos del tratamiento están dirigidos al alivio del dolor isquémico, cicatrización de trastornos tróficos, prevención de pérdida de tejido y del miembro involucrado, apuntando a una mejora en la función y calidad de vida.

En general las guías y consensos nos dirigen al tratamiento endovascular en aquellos pacientes con lesiones más simples conocidas como TASC A y B, y quirúrgico en aquellos con lesiones más complejas TASC C y $\mathrm{D}^{114}$. Sin embargo, en este territorio, debido a los malos lechos, alto riesgo quirúrgico, edad, fragilidad y comorbilidades, el tratamiento endovascular es de primera elección ${ }^{115,116}$.

\begin{tabular}{|l|c|c|}
\hline $\begin{array}{l}\text { Recomendaciones para revascularización en pacientes con } \\
\text { lesiones infrapoplíteas } 117\end{array}$ & Clase & $\begin{array}{c}\text { Nivel de } \\
\text { evidencia }\end{array}$ \\
\hline $\begin{array}{l}\text { Ante la necesidad de revascularización infrapoplítea pri- } \\
\text { mero debe considerarse el abordaje endovascular. }\end{array}$ & II a & C \\
\hline $\begin{array}{l}\text { Para lesiones infra-poplíteas la ATP debería ser la técnica } \\
\text { de elección considerando al stent ante fracaso de la otra. }\end{array}$ & Ila & C \\
\hline $\begin{array}{l}\text { En pacientes con anatomía compleja y posibilidad de } \\
\text { conducto autólogo la cirugía debe ser considerada. }\end{array}$ & I & A \\
\hline
\end{tabular}

\begin{tabular}{|l|c|c|}
\hline $\begin{array}{l}\text { Recomendaciones para el manejo de isquemia crítica de } \\
\text { miembros inferiores } 118\end{array}$ & Clase & $\begin{array}{c}\text { Nivel de } \\
\text { evidencia }\end{array}$ \\
\hline $\begin{array}{l}\text { La revascularización es el procedimiento de elección } \\
\text { para el salvataje del miembro si fuera técnicamente po- } \\
\text { sible. }\end{array}$ & I & A \\
\hline $\begin{array}{l}\text { La estrategia endovascular debe ser considerada como } \\
\text { la } 1^{\text {a } o p c i o ́ n, ~ s i ~ f u e s e ~ p o s i b l e . ~}\end{array}$ & Ilb & B \\
\hline
\end{tabular}

\subsection{Objetivos hemodinámicos}

Desde hace años ${ }^{119}$ se sostiene que es necesario tener permeable al menos una de las 3 arterias infrapatelares (peronea o tibiales) en línea directa hacia el pie para que la revascularización sea eficiente y el salvataje del miembro sea efectivo, prefiriéndose de ser posible la revascularización de alguna de las tibiales.

En estudios más recientes ${ }^{120}$, incorporando el concepto de angiosoma en pacientes con isquemia crítica y lesiones aisladas en vasos infrapatelares, se comparó la revascularización directa definida como tal cuando se logró re-permeabilizar la o las arterias que irrigan el sitio de ulceración o gangrena con la revascularización indirecta donde solo se logró la irrigación por colaterales. Observándose una mayor sobrevida libre de amputación, menor necesidad de amputación, con una clara mejor evolución alejada cuando se logra la revascularización directa. 
El objetivo de la intervención es obtener al menos uno, pero preferiblemente lograr la revascularización completa hasta la parte distal del pie. Debiera hacerse todo lo posible para tratar más de un vaso tibial, especialmente en casos de poco riesgo de procedimiento adicional, ya que esto mejora el rescate de extremidades ${ }^{121}$.

\subsection{Sitio de abordaje}

Si bien lo habitual es poder realizar los procedimientos por punción anterógrada, en algunos casos como pacientes muy obesos o lesiones en origen de femoral superficial el crossover puede ser una alternativa, en cuyo caso debiéramos medir la distancia desde el sitio de punción hasta la lesión a tratar para asegurarnos que podamos hacer el tratamiento con los materiales disponibles. En algunos casos menos comunes pudiéramos hacer un abordaje desde el pie, habitualmente combinado con uno anterógrado ${ }^{122}$. Nos referiremos específicamente sobre este particular en el Anexo II.

\subsection{Complejidad de las lesiones}

Oclusiones: Además de la habitual coexistencia de obstrucciones a distintos niveles (sectores ilíacos y Femoro-poplíteo) debemos tener en cuenta la altísima prevalencia de oclusiones ${ }^{123}$ en este territorio con su consecuente impacto negativo en el éxito de la revascularización. En pacientes con isquemia crítica se observan oclusiones largas de más de $10 \mathrm{~cm}$ en cerca del $50 \%$, oclusiones de los tres vasos principales infrapatelares en el 30\%, con necesidad de revascularizar además algún vaso distal a nivel del pie en alrededor del $50 \%{ }^{124}$. Ante la necesidad de revascularizar debiéramos tener presente las distintas técnicas posibles en el manejo de las oclusiones de este territorio.

Calcificaciones: Otro de los problemas relacionados es la calcificación ${ }^{125}$, que puede ser de la íntima excéntrica y voluminosa a menudo asociada con aterosclerosis, o de la media concéntrica y linear asociada con diabetes e insuficiencia renal. Debemos tener en cuenta que su presencia se asocia con un mayor riesgo de amputación. Por supuesto no debemos olvidar que la edad favorece su presencia. Obviamente este tipo de calcificaciones se asocian con menor éxito del procedimiento y mayor incidencia de complicaciones. Cuando hay calcificación se requiere algún dispositivo asociado, pero lamentablemente todavía no contamos con alguno óptimo en este territorio.

Longitud: Las lesiones de este territorio suelen caracterizarse por ser difusas, largas y en tándem, situación que complejiza aún más los procedimientos.

\subsection{Dispositivos elegibles}

Balón: Sin duda es la primera herramienta ${ }^{126}$ que solemos usar y en este territorio es una de las más eficientes. Debido a la habitual presencia de lesiones en tándem y/o largas es sumamente útil el uso de balones de distintas longitudes optimizando los procedimientos con insuflaciones prolongadas con el objeto de "sellar" las disecciones ${ }^{126}$. Creemos además que es de buena práctica luego de des-insuflar esperar varios minutos (10' a 15') con el objeto de verificar la estabilidad (ausencia de retroceso elástico) del resultado obtenido, antes de finalizar el procedimiento.

Stents: Si bien son de uso sistemático en otros territorios vasculares como el coronario, en miembros inferiores debemos reservarlos para situaciones especiales ${ }^{118}$ dadas por resultado insuficiente, retroceso elástico persistente, protru- sión de placa y/o disecciones con compromiso de flujo. También es de uso electivo en las anastomosis de by-pass. Cuando necesitamos colocar un stent en el territorio infra-patelar debemos tener presente la posibilidad de compresiones extrínsecas de los mismos. En la arteria poplítea Infrapatelar debemos evitar el uso de stents, pero ante la necesidad debiéramos elegir los del tipo autoexpandibles de nitinol. En la región siguiente correspondiente al tronco tibioperoneo y $1 / 3$ superior de peronea y tibiales podemos utilizar stents balón expandibles liberadores de droga, adaptándose adecuadamente los de uso coronario debido al diámetro. Evitar colocar stents en la poplítea y en el 1/3 medio y distal de vasos tibiales o peronea. No poner stents en el pie. Con estas premisas y uso sistemático de balones largos suelen utilizarse stents en solo el $2 \%$ de los casos.

Balón con drogas: Sin duda es un territorio con altísimas chances de restenosis entonces hoy cabe preguntarse porque no utilizar balón con drogas. Lógicamente el DEB se ha inventado para disminuir la reestenosis y comparado con el balón convencional, aún en este territorio logra el objetivo ${ }^{127}$. Sin embargo, comparte las limitaciones del balón convencional. Especialmente en este territorio donde el calcio es un problema condicionando la adecuada absorción de la droga y favoreciendo el retroceso elástico ${ }^{128}$.

Stent liberador de droga: Lógicamente si comparamos balón liberador de droga versus stent liberador de droga (en aquellos pacientes en los que pudiera usarse por el tipo y localización de la lesión a tratar) la obstrucción inmediata y restenosis es mucho menor en los tratados con DES ${ }^{129}$, siendo su uso limitado a sectores proximales de vasos mayores a $2.5 \mathrm{~mm}$.

\subsection{Abordaje de las arterias del pie}

Otro aspecto importante es considerar cuando debiéramos o no tratar las arterias del pie. En una clasificación del arco vascular del pie ${ }^{130}$ según la permeabilidad o no de las arterias pedias y plantares se describen 3 tipos:

a) Tipo 1 están permeables las 2 ,

b) Tipo 2 hay una permeable y otra ocluida y

c) Tipo 3 están ocluidas las 2 .

En casos de isquemia crítica, los pacientes con el tipo 3 (ambas arterias ocluidas) tendrían una peor cicatrización, los del tipo 2 un poco mejor, y los del 1 la mejor posible. De forma tal que cuando tenemos que tomar una decisión en la sala de Hemodinamia y se ve un insuficiente blush hacia el sitio lesionado y siguiendo el concepto de angiosoma, estaría indicada la angioplastia a dicho nivel.

\subsection{Pie Diabético}

La isquemia crónica del miembro inferior (ICM) en los pacientes diabéticos se encuentra asociada a un aumento significativo de morbi-mortalidad, así como una severa restricción en la calidad de vida. ${ }^{131}$ A pesar de su adverso pronóstico, la mayoría de los pacientes no poseen una evaluación vascular, con diagnóstico preciso y/o intervención terapéutica en el año previo a su amputación ${ }^{132}$. La revascularización en ICM es el tratamiento preferencial en plan de evitar amputación del miembro comprometido, úlceras recurrentes y/o compromiso del miembro contralateral. Las opciones en revascularización incluyen cirugía, tratamiento endovascular o abordajes híbridos ${ }^{133,134,135}$.

El estudio BASIL comparó las estrategias invasivas, no observándose diferencias en la sobrevida libre de amputación. Sin embargo, la tecnología no fue comparable a la actual (an- 
gioplastia con balón), la cirugía fue asociada a mayor comorbilidad, mayor estadía hospitalaria en unidades intensivas y por lo tanto mayor costo ${ }^{136}$.

La decisión debe ser personalizada, liderada a través de un equipo multidisciplinario, considerando además de la anatomía a tratar (disponibilidad de vena, lecho distal, runoff, calcificación, procedimientos previos), la edad, comorbilidades, expectativa de vida, función renal, riesgos de la anestesia y el acuerdo con el paciente.

En los últimos años, secundario a un gran avance tecnológico y resultados clínicos alentadores, el tratamiento endovascular ha sido aceptado como la estrategia terapéutica en gran parte de estos pacientes. La principal ventaja es la baja incidencia de complicaciones $(0,5 \%$ - $4 \%)$ y el alto éxito técnico ${ }^{137,138}$. Sin embargo, el abordaje conjunto y personalizado se encuentra por encima, ya que los resultados se pueden ver condicionados por la complejidad y extensión de las lesiones, así como la estrategia técnica adoptada.

Para determinar el mejor método de revascularización debemos pensar previamente en el riesgo de la intervención y la durabilidad del tratamiento. UN correcto flujo de entrada como de salida es necesario para garantizar el éxito del segmento tratado. Es por ello necesario un método de imágenes adecuado para planear una estrategia óptima y racional, que permita el éxito de la intervención, así como la durabilidad de la misma.

\begin{tabular}{|l|c|c|}
\hline $\begin{array}{l}\text { Recomendaciones para la revascularización en el pacien- } \\
\text { te con pie diabético }\end{array}$ & Clase & $\begin{array}{c}\text { Nivel de } \\
\text { evidencia }\end{array}$ \\
\hline $\begin{array}{l}\text { El manejo mediante un equipo multidisciplinario resul- } \\
\text { ta fundamental para alcanzar el éxito terapéutico y los } \\
\text { objetivos de la revascularización }\end{array}$ & I & A \\
\hline $\begin{array}{l}\text { El tratamiento endovascular es razonable como trata- } \\
\text { miento de elección en isquemia crítica cuando la ana- } \\
\text { tomía es favorable }\end{array}$ & I & B \\
\hline
\end{tabular}

\section{TRATAMIENTO GUIADO POR ANGIOSOMA EN ISQUEMIA CRÍTICA DE MIEMBRO}

Los pacientes con isquemia crítica presentan compromiso de múltiples segmentos, afectando el lecho infra poplíteo en el $67 \%$ de los $\operatorname{casos}^{139-141}$. Históricamente, en los pacientes portadores de lesiones tróficas, la revascularización quirúrgica era suficiente cuando se establecía una vía de flujo directo al pie. Sin embargo, las estrategias actuales de tratamiento abordan al paciente siguiendo un criterio guiado por el Angiosoma. En actuales análisis sobre pacientes diabéticos y lesiones tróficas, este enfoque resulta en reducción de amputaciones curación de la herida en menor tiempo y completa a los 12 meses de seguimiento ${ }^{142-146}$. A pesar de que la revascularización directa sobre el angiosoma isquémico impresiona lógica y prometedora, luego de estudios retrospectivos y de baja escala, en la práctica diaria no siempre es factible, en función de la anatomía, alentándose la revascularización indirecta posible.

La angioplastia con balón continúa siendo una herramienta útil y eficaz. El estudio DEBATE-BTK randomizó la angioplastia convencional con balón vs los balones liberadores de fármaco (DEB), objetivando una reducción de restenosis y necesidad de nueva revascularización en la lesión tratada con estos últimos.
El estudio IN.PACT DEEP observó un mayor, pero no significativo, riesgo de amputación en el grupo DEB. Múltiples estudios se encuentran evaluando la eficacia y la seguridad de estos dispositivos a nivel infra poplíteo, limitando su uso en la práctica actual ${ }^{147,148}$.

Una de las limitaciones de la angioplastia con balón continúa siendo el retroceso elástico del vaso o la disección que compromete el flujo, mitigado potencialmente con los stents. Estos han sido comparados en múltiples experiencias de pequeño volumen, con la indicación de implantación focal, obteniendo con ellos una reducción de riesgo de restenosis y revascularización de la lesión tratada comparada a stents convencionales o balón ${ }^{149,150,151}$. Frente a la necesidad en la colocación de un stent, la utilidad de estos se limita a regiones focales, evitando zonas de flexión. Estudios adicionales son necesarios para confirmar si la mayor permeabilidad del vaso, específicamente en pacientes portadores de isquemia crítica, se traduce en mejoría clínica. Por otro lado, el punto final para evaluar una estrategia de tratamiento en este tipo de pacientes debe apuntar hacia la prevención de la amputación y la curación de la herida y no únicamente en la permeabilidad del vaso.

Nuevas iniciativas (BEST-CLI, BASIL II, BASIL III) proveerán información para definir el tratamiento más adecuado, de alta calidad y costo efectivo para esta compleja población.

\begin{tabular}{|l|c|c|}
\hline $\begin{array}{l}\text { Recomendaciones para la revascularización guiada por } \\
\text { angiosoma en isquemia crítica }\end{array}$ & Clase & $\begin{array}{c}\text { Nivel de } \\
\text { evidencia }\end{array}$ \\
\hline $\begin{array}{l}\text { Se recomienda el abordaje guiado por angiosoma } \\
\text { siempre que resulte factible }\end{array}$ & Ila & C \\
\hline
\end{tabular}

\section{ANGIOPLASTIA EN SEGMENTOS DE FLEXO-COMPRESIÓN. ANGIOPLAS- TIA EN EL TERRITORIO DE LA ARTERIA POPLÍTEA}

El implante de stent en la Arteria Poplítea (AP) es una opción terapéutica para varias enfermedades que afectan esta arteria, incluyendo aterosclerosis, aneurismas e injuria con pseudo-aneurismas y/o formación de fístula arteriovenosa 152-158. Debido a que la AP está expuesta a los movimientos de flexión de la rodilla, es aceptado el uso de stent de nitinol autoexpandible y stent-graft por su propiedad "crush reversible”. Esta condición es ventajosa en áreas del organismo expuestas a compresión extrínseca y movimientos ${ }^{158}$. Sin embargo, se han reportado fracturas de stent autoexpandibles de nitinol, incluso en aquellos implantados en la AP ${ }^{159}$. Se cree que la compresión de los vasos y el movimiento promueven el desarrollo de "puntos bisagras" (PB) que llevan en última instancia a la fractura del stent ${ }^{152,160}$.

En la actualidad hay estudios randomizados que reportan bajo índice de fractura a nivel del territorio de femoropoplíteo ${ }^{159,161,162}$. Sin embargo, sólo tuvieron en cuenta el segmento proximal de la arteria poplítea, el cual generalmente se encuentra por arriba del sitio de flexión principal. Por otro lado, existen reportes de casos clínicos con fracturas con pérdida de la integridad estructural del stent implantado en la AP ${ }^{160}$. A la luz de la evidencia disponible, se sugiere al momento decidir el tratamiento de la AP la realización de una angiografía en vista lateral con la pierna en flexión de aproximadamente $90^{\circ}$ lo cual permite: 
Evidenciar con precisión los sitios de flexión a los que es sometida la arteria

$\mathrm{Su}$ adecuada correlación con las lesiones a tratar.

La ocasional detección de lesiones que no se evidencian con la rodilla extendida.

Identificación de lesiones en sitios que permanecen rectos durante la flexión y que podrían ser abordados con el empleo de stents.

En caso de lesiones que coincidan con el sitio de flexión, se aconseja siempre procurar realizar el tratamiento del dicho territorio sin colocar stents. El desarrollo de los balones liberadores de droga y actualmente de stents dedicados ofrecen una excelente alternativa terapéutica para ello. Los nuevos dispositivos diseñados específicamente para este sector como el stent mimético, se presentan además como una herramienta útil frente al fracaso del balón ${ }^{162}$.

\section{INDICACIONES PARA EL TRATAMIENTO QUIRÚRGICO}

Los pacientes con isquemia crítica de miembros inferiores (ICM) en término generales requieren de algún tipo de intervención. Tal son los pacientes clasificados como Fontaine III y IV o Rutherford 4 a 6. Los más recientes consensos europeos ${ }^{163}$ definen la ICM como: Dolor de reposo isquémico persistente o recurrente que requiere analgesia opiácea durante 2 semanas y presión sistólica en el tobillo inferior a $50 \mathrm{~mm} \mathrm{Hg} \mathrm{o}$ presión sistólica en pié inferior a $30 \mathrm{~mm} \mathrm{Hg}$; o ulceración o gangrena del pie o los dedos de los pies y la presión sistólica del tobillo inferior a $50 \mathrm{~mm} \mathrm{Hg}$; o presión sistólica en pie inferior a $30 \mathrm{~mm} \mathrm{Hg}$. Al 1 año, sólo el 5\% tendrá una supervivencia libre de amputación si no recibe un procedimiento de revascularización. En la práctica, estos datos indican que estos pacientes de riesgo quirúrgico extremadamente alto y con isquemia crítica pueden ser manejados quirúrgicamente.

La meta del tratamiento invasivo del paciente con ICM implica la necesidad de revascularización para mejorar la perfusión y conseguir la cicatrización. La revascularización directa debe hacer desaparecer el dolor, curar las lesiones tróficas, mantener un miembro funcionante y restablecer el estado funcional pre-patología.

Pero, en los últimos años, el desarrollo de nuevas tecnologías mini-invasivas mediante cirugía endovascular ha virado el abordaje primario de la revascularización. Las Guías Prácticas (Task Force) del American College of Cardiology / American Heart Association (ACCF / AHA) ${ }^{164}$ proponen una actualización en el tratamiento de la enfermedad oclusiva de los miembros inferiores, centrada en el proceso de revisión de las recomendaciones de las guías existentes dada la nueva tecnología y evidencia. El objetivo primordial fue comparar el tratamiento quirúrgico versus el tratamiento endovascular, especialmente referidas a la expectativa de vida. Las siguientes recomendaciones se enfocan al modo de abordaje.

Para los pacientes con isquemia crítica de MMII y una esperanza de vida estimada en menos de 2 años o en pacientes en los que un conducto de vena autóloga no está disponible, la angioplastia con balón es razonable como procedimiento inicial para mejorar el flujo distal (Clase IIa, Nivel de evidencia B).

Por el contrario, para los pacientes con isquemia crítica de MMII y una esperanza de vida estimada de más de 2 años, la cirugía de By-pass, cuando sea posible y cuando un conduc- to de vena autóloga está disponible, es razonable como tratamiento inicial para mejorar el flujo sanguíneo distal (Clase IIa, Nivel de evidencia B).

Estas recomendaciones fueron realizadas examinando los resultados del estudio multicéntrico BASIL (Bypass versus Angioplasty in Severe Ischemia of the Leg) bajo el aval del United Kingdom National Institute of Health Research and Health Technology Assessment Programme ${ }^{166}$. Este estudio también ha confirmado que los resultados tras la cirugía con prótesis, en lugar de injerto venoso, eran extremadamente pobres. Incluso la angioplastia con balón, siempre que fuera posible, debe ser preferible al bypass protésico aún en pacientes con una esperanza de vida mayor a 2 años. Es importante en este estudio ver además que el intento fallido de revascularización percutánea determinó un peor pronóstico para un bypass de rescate (Figura 3). El concepto es que, en términos generales, con cualquier procedimiento de revascularización, los resultados pueden mejorar o empeorar clínicamente, dependiente del éxito o fracaso del acto quirúrgico, pero no quedar igual, como si nada se hubiera hecho. Una angioplastia fallida, generalmente ocluye además del territorio tratado, parte de la circulación colateral. Un bypass fallido agrega a la gangrena las heridas quirúrgicas que deberán cicatrizar, además de la sección de circulación colateral que habitualmente se encuentra en el plano muscular o subcutáneo (Figura 3).

La Sociedad Europea de Cirugía Vascular, publicó un Consenso algo más completo y detallado, con una orientación más anatómica que clínica ${ }^{163}$. En síntesis, este refiere que cuando la anatomía arterial es favorable, es mejor realizar un procedimiento percutáneo, que implica entre otras cosas, una menor agresividad para el paciente. Cuando la anatomía arterial es compleja, con múltiples segmentos ocluidos, calcificados y con pequeñas arterias tibiales, la opción de cirugía abierta con vena, parece ser la mejor opción.

Por su parte, la Sociedad Americana de Cirugía Vascular ha efectuado una serie de recomendaciones basadas en la clasificación WiFi de la Sociedad de Cirugía Vascular (SVS) ${ }^{165}$. La misma considera una combinación de juicio clínico con la interpretación cuidadosa de evaluaciones objetivas de la perfusión, las características morfológicas de la herida y la infección (Figura 4), la cual es necesaria para seleccionar adecuadamente a los pacientes para revascularización o con mayor posibilidad de amputación. Además, recomienda que, en pacientes con enfermedad oclusiva sintomática, con un segmento arterial ocluido largo y difuso, y en presencia de un buen conducto autólogo, el bypass es la técnica de revascularización más efectiva. En el contexto de pérdida de tejido y diabetes, el bypass protésico es inferior al conducto venoso.

La Clasificación WiFi determina un puntaje y en base a este, el riesgo de amputación al año (Figura 5) y la recomendación de revascularizar al paciente (Figura 6).

Recomendaciones en el tratamiento del segmento aortoiliaco El bypass aortofemoral suele ser el tratamiento de elección para la enfermedad difusa oclusiva del segmento aortoilíaco en los pacientes que son candidatos quirúrgicos adecuados. (Indicación Clase IIb, Nivel de evidencia B). Los bypass extraanatómicos (axilofemoral, axilobifemoral, femorofemoral cruzado) acompañados de una baja tasa de permeabilidad, deben ser realizados en pacientes que no tengan otra posibilidad de revascularización. 
Sin embargo, el tratamiento endovascular debe ser considerado la estrategia primaria para pacientes con lesiones aortoilíacas, con frecuencia, previo o en conjunción, con un procedimiento de revascularización distal.

\section{Recomendaciones de tratamiento en el segmento femoropoplíteo}

La endarterectomía es el tratamiento estándar en la enfermedad aterosclerótica de la arteria femoral común y proporciona excelentes resultados con baja morbilidad y mortalidad. Un concepto clave en revascularización de miembros es la importancia de la permeabilidad de la arteria femoral profunda, responsable en muchos casos de tener un miembro viable. La revascularización de la arteria femoral profunda se puede considerar en los pacientes con isquemia crítica, sin opciones para la restauración del flujo sanguíneo continuo desde el segmento aorto-ilíaco a la arteria poplítea, en relación con estenosis hemodinámicamente significativa de la misma. Sobre la base de pruebas actualmente disponibles, la profundoplastia quirúrgica (endarterectomía femoral con arteriorrafia con parche) se prefiere sobre la recanalización endovascular, debido a una tasa relativamente alta de fallos post angioplastia. La profundoplastia puede ser de un valor adicional en la preservación de la articulación de la rodilla, cuando la amputación es inevitable.

Cuando la vena autóloga está disponible como conducto, la cirugía de bypass es el tratamiento preferido para lesiones largas $(>15 \mathrm{~cm})$ de la arteria femoral superficial (AFS), especialmente en los pacientes más jóvenes. Aunque el resultado después de un primer abordaje endovascular es igual en el corto plazo que el de la cirugía de bypass protésico para lesiones largas de la AFS, en los pacientes con isquemia crítica, el bypass da mejores resultados en los pacientes de bajo riesgo y debe ser de preferencia en pacientes con la longevidad estimada >2 años. (Indicación Clase IIa, Nivel de evidencia B)

\section{Recomendaciones en el tratamiento de las lesiones infrapoplíteas}

El tratamiento endovascular de las arterias infra-poplíteas tiene el potencial de alcanzar tasas similares de salvataje de la extremidad con una menor morbilidad y mortalidad que los procedimientos quirúrgicos convencionales. No obstante, el tratamiento quirúrgico debe ser considerado para las lesiones anatómicas más complejas de los vasos tibiales, o en caso de fallo endovascular y persistencia de los síntomas clínicos. Lesiones focales cortas, infra-poplíteas, pueden ser tratadas con stent balón expandibles liberadores de fármacos, con una mejor tasa de permeabilidad. Especialmente en el territorio tibial, la necesidad de revascularización completa y respetando los angiosomas de la lesión son dos características claves al momento de obtener efectivos resultados endovasculares. En resumen, cuanto mayor sea la cantidad de vasos permeables y más directo el flujo (angiosoma) mejor será el resultado clínico obtenido por la angioplastia.

La vena safena interna es superior a cualquier otro material y se debe preferir como injerto en los By-pass a las arterias infra-poplíteas o tibiales. Cuando la vena safena interna no está disponible o no es apta, el uso de injertos de vena alternativos (de un solo segmento o compuesto) es preferible a la realización de un bypass con vena preservada o al bypass con PTFE.

\section{ANEXO I. TÉCNICA Y RECOMENDACIO- NES PARA MEDICIÓN DEL ITB}

El Doppler direccional detecta el sentido del flujo, mientras que el Doppler no direccional o continuo no, por las limitaciones del equipo manual. La sonda de $8 \mathrm{MHz}$ permite mantener con más facilidad el contacto con el vaso durante el inflado y desinflado del manguito, por lo que es el más utilizado. La sonda con ancho de $4 \mathrm{MHz}$ es útil para detección de vasos profundos, y la de $5 \mathrm{MHz}$ es empleada para vasos profundos y o miembros edematosos; son complementarias. Sin embargo, la sonda de $8 \mathrm{MHz}$ con Doppler continuo cubre prácticamente todas las necesidades.

\section{Elementos necesarios:}

1- Aparato de Doppler continuo portátil con sonda de haz de $8 \mathrm{MHz}$ ancho.

2- Esfigmomanómetro convencional con manguito de 12 cm de ancho.

3- Gel conductor para ultrasonido.
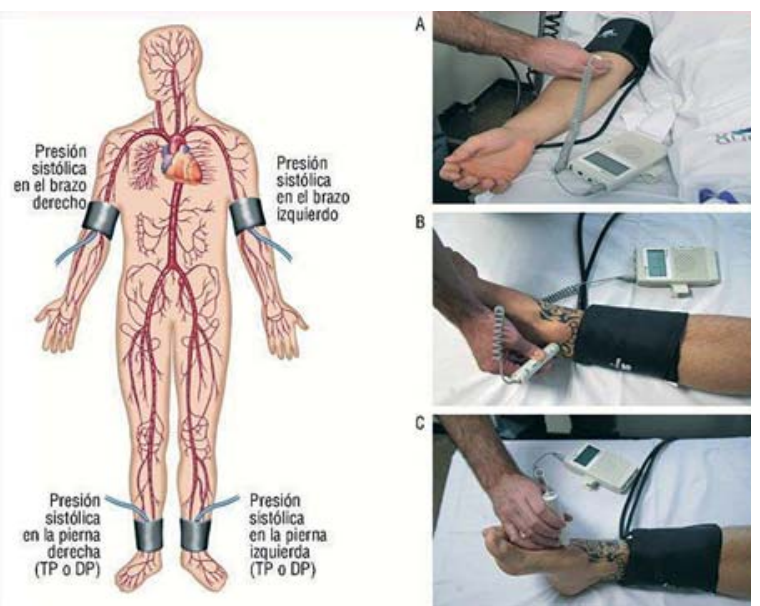

Figura 7. Imagen tomada de Rev Esp Cardiol Supl. 2009; 09 (D):11

\section{Técnica del procedimiento:}

1. Paciente en decúbito dorsal.

2. Reposo en la camilla durante diez minutos.

3. Medición de la presión arterial sistólica con el transductor de ambas arterias braquiales en ambos brazos.

4. Medición de la presión arterial de los miembros inferiores:

- Colocación del borde inferior del manguito encima de los tobillos.

- Medición de las presiones sistólicas de las arterias Pedia y Retromaleolar.

- Localizar la arteria pedia fuera del tendón extensor del primer dedo.

- Localizar la arteria tibial posterior entre el maléolo interno y el calcáneo

- El transductor debe colocarse en sentido contrario al flujo arterial con un ángulo entre $45^{\circ}$ a $90^{\circ}$.

- El manguito se insufla hasta $20 \mathrm{~mm}$ de $\mathrm{Hg}$ por encima de la presión sistólica de la arteria braquial de referencia.

- Posteriormente se irá desinflando lentamente hasta la aparición de la señal Doppler nuevamente.

5- Cálculo ITB: La presión sistólica más elevada del tobillo se divide por la presión sistólica más elevada del miembro superior * 
6- Se definirá como ITB del miembro al valor más bajo de las dos arterias

ITB $=\frac{\begin{array}{c}\text { Mayor presión sistólica } \\ \text { del tobillo }\end{array}}{\begin{array}{c}\text { Mayor presión sistólica } \\ \text { arteria braquial }\end{array}} \quad$ (método tradicional)*

*(Basada en las guías de la American Heart Association e Inter-Society Consensus for Management of Peripheral Arterial Disease)

ITB $=\frac{\begin{array}{c}\text { Mayor presión sistólica } \\ \text { del tobillo }\end{array}}{\begin{array}{c}\text { Mayor presión sistólica } \\ \text { arteria braquial }\end{array}}$ (método alternativo)

Ejemplo:

$\mathrm{ITB}$ tradicional $=\frac{130}{125}=1,04 ; \mathrm{ITB}$ alternativo $=\frac{110}{125}=0,88$

La concordancia de los signos y síntomas se ha hecho con el cálculo del ITB tradicional, tal como se refiere en el texto.

\section{ANEXO II. NUEVOS ABORDAJES: ACCESOS NO CONVENCIONALES PARA ANGIOPLASTIA DE MMII}

El acceso por vía femoral, anterógrado o por cross-over desde el miembro contralateral, constituye la vía habitual para la angioplastia de las arterias de los miembros inferiores.

Sin embargo, en alrededor del $10-20 \%$ de los casos realizados por vía femoral se produce el fracaso técnico por imposibilidad de cruzar la lesión ${ }^{167}$. Cuando esto sucede, el acceso retrógrado es una opción a tener en cuenta, ya que se asocia a una probabilidad $>85 \%$ de éxito técnico en casos en que ha fracasado la vía anterógrada convencional ${ }^{168,169}$.

El acceso retrógrado puede obtenerse a través de:

Arteria poplítea: permite acceder fácilmente a lesiones de arterias Femorales y por su proximidad a la misma, la fuerza de empuje puede ser un factor importante para recanalizar oclusiones de largo trayecto. Sin embargo, problemas con la incomodidad que produce su trayecto posterior y la falta de un plano de compresión adecuado para la hemostasia al finalizar el procedimiento lo convierten en un acceso poco atractivo.

Acceso tibio-pedal: permite tratar lesiones infrapatelares y del segmento femoropoplíteo. El principal inconveniente con este acceso tiene relación con el fino calibre de los vasos y las dificultades en la punción que esto genera.

Los tres puntos de acceso que se relacionan con mayor tasa de éxito y menor tasa de complicaciones son ${ }^{170}$ :

1. Tibial anterior distal.

2. Tibial posterior distal.

3. Dorsal del pie.

Con la acumulación de experiencia pueden obtenerse otros puntos de acceso más proximales e inclusivo a través de arteria peronea.
Debido a la falta de pulsatilidad que produce la enfermedad arterial obstructiva, usualmente la punción debe guiarse con alguna de las siguientes modalidades:

- Radioscopia / road mapping: Algunas veces la extensa calcificación de los vasos permite identificarlos sin medio de contraste. En otras oportunidades, en pacientes colaboradores, el road mapping administrando contraste por la vía anterógrada previamente obtenida permite guiar la punción. La principal desventaja de esta estrategia es la radiación que recibe el operador en sus manos.

- Ultrasonido: el Doppler color permite identificar el flujo, utilizando luego la escala de grises para punzar la pared anterior del vaso. Esta estrategia requiere de la disponibilidad de un equipo de ultrasonido en la sala y de la asistencia de un operador experimentado o el entrenamiento del intervencionista en esta técnica.

Conseguida la punción del vaso y dependiendo de la necesidad de soporte, puede optarse por colocar introductores 4 o $5 \mathrm{~F}$ o intentar recanalizar el vaso con cuerdas con alto poder de penetración y su posterior exteriorización por el acceso Femoral concomitante.

\section{Comentarios y recomendaciones prácticas:}

Lo expuesto hasta aquí se basa en serie de casos, en un manual práctico de acceso tibio-pedal y opinión de expertos, sin que existan datos a mayor escala que puedan ofrecer un mejor nivel de evidencia para las siguientes recomendaciones:

1. El acceso tibio-pedal es seguro y efectivo en casos de fracaso de la vía anterógrada convencional. Indicación Clase II a, Nivel de evidencia C

2. Su plano de compresión y superficialidad lo hacen más seguro que el acceso retrógrado poplíteo. Indicación Clase II a, Nivel de evidencia C

3. Al inicio de la experiencia, los puntos de acceso que se asocian con mayor tasa de éxito técnico y menor probabilidad de complicaciones son, el tercio distal de las arterias tibiales anterior y posterior y la arteria pedia. Indicación Clase II a, Nivel de evidencia $\mathbf{C}$

4. La guía ultrasonográfica para obtener el acceso es de primera elección para limitar la irradiación de las manos del operador. Sin embargo, esta estrategia requiere mayor complejidad en la sala de hemodinamia y formación técnica de los operadores. Indicación Clase IIa, Nivel de evidencia $\mathrm{C}$

\section{ANEXO III. ALTERNATIVAS ENDOVAS- CULARES FRENTE AL FRACASO DE LAS TECCNICAS QUIRÚRGICAS}

En casos de trombosis aguda del bypass: trombolisis dirigida por catéter, trombo aspiración, trombectomía y, eventualmente, angioplastia y/o stent primario.

- La terapia trombolítica dirigida por catéter es el proceso de lisis de un trombo de manera percutánea utilizando equipos especiales de intervención mediante la infusión de fármacos o mediante el uso combinado de fármacos y dispositivos mecánicos.

- La trombolisis farmacológica se define aquí como el proceso de disolución del trombo a través de la infusión del agente trombolítico mediante un catéter.

- La trombectomía (trombolisis mecánica) se define en el presente documento como la disrupción mecánica del trombo. 
- La trombolisis fármaco-mecánica, es la disrupción mecánica del trombo combinado con trombolisis farmacológica.

\subsection{Trombolisis}

El tratamiento quirúrgico estándar de la oclusión del injerto de bypass ha sido la trombo-embolectomía con procedimientos adicionales realizados según sea necesario para tratar cualquier lesión oclusiva subyacente. Este enfoque produce resultados bastante desiguales. Alternativamente, algunos autores abogan por la eliminación y el reemplazo del injerto en un intento de mejorar el resultado.

El manejo quirúrgico de la oclusión del injerto de bypass se asocia con una significativa morbi-mortalidad. Muchos pacientes tienen altísimo riesgo para someterse a una cirugía ${ }^{171}$. Por este motivo, el tratamiento fibrinolítico se presenta como una alternativa válida. Si bien la infusión sistémica de trombolíticos fue la alternativa inicial, actualmente no es la elección, dada la alta tasa de complicaciones que presenta y la baja efectividad. La Trombolisis Dirigida por Catéter (TDC) es la vía de tratamiento más seleccionada. Además, la TDC no solo puede recanalizar al conducto obstruido, sino que también permite solucionar la lesión subyacente mediante angioplastia.

\section{Técnica endovascular:}

Vías de abordaje: en la mayoría de los pacientes el abordaje es contralateral (retrógrada) debido a que los conductos suelen tener origen en la arteria femoral común o tercio proximal de la arteria femoral superficial. En casos de By-pass de tercio distal de la arteria femoral superficial, se puede utilizar la vía homolateral (anterógrada). En el By-pass axilo-femoral, el abordaje humeral o radial es posible. En ambos casos, durante la punción se debería tratar de punzar solo una pared para evitar hematomas en sitio de punción. Se recomienda siempre punción eco-guiada.

Catéteres: Usualmente se utilizan de diámetros de 4 o 5 French. Procedimiento: Se debe intentar cruzar la totalidad del conducto obstruido con guía hidrofílica. De hecho, la capacidad de cateterizar el bypass y cruzar la oclusión con una guía hidrofílica tiene un efecto significativo en el resultado, aumentado la tasa de éxito en forma significativa. Sobre esta guía, se suele utilizar un catéter de apoyo o sostén ${ }^{172}$.

Esto se conoce como "test de cruce con guía". Se supone que, si se logra cruzar fácilmente y acceder a un lecho distal aceptable, la probabilidad de éxito técnico es mucho mayor. Se debe constatar adecuado lecho distal y luego se procede a la infusión del agente trombolítico. Una vez finalizada la misma, se efectúa el tratamiento de la lesión subyacente mediante angioplastia con o sin implante de stent, de acuerdo con el resultado obtenido post balón.

Una técnica alternativa para facilitar la liberación de la lisis intra trombo es realizar punción directa del injerto. Esta técnica es particularmente útil en los pacientes con prótesis extra-anatómicas ${ }^{173}$.

Se requieren antibióticos profilácticos cuando se practica la punción directa de los injertos protésicos.

\section{Vías de infusión:}

Las técnicas locales establecidas de administración de fármacos trombolíticos son:

1. La infusión intraarterial regional: no selectiva, catéter proximal al trombo sin entrar a la lesión y la opción selectiva, donde la punta del catéter está dentro de la oclusión.
2. La infusión intra trombo: el agente fibrinolítico se suministra dentro del trombo con la punta del catéter incrustada a ese nivel. Esta es la técnica más comúnmente utilizada, y se ha informado que en la mayoría de los casos se consigue una trombosis completa y un mayor beneficio ${ }^{174}$.

3. Bolo intra-trombo: es la infusión inicial del agente trombolítico concentrado dentro del trombo, con el objeto para saturar el área del vaso ocluido de la droga. Se puede usar un catéter de un solo agujero distal o uno multiperforado. También se han propuesto guías de infusión especialmente diseñadas. Se comienza a nivel distal y se va retirando el catéter a lo largo del conducto trombosado ${ }^{175}$.

4. Infusión paso a paso: se comienza con la infusión en el sector proximal del trombo. A medida que se logra la disolución, se progresa hacia distal ${ }^{176}$.

5. Infusión continua: es la técnica estándar de infusión intra-trombo. El catéter está conectado a una bomba con suministro constante del agente trombolítico.

6. Infusión graduada: dosis tiempo dependiente. Se administra una dosis alta de fármaco en las primeras horas del procedimiento y luego una dosis de mantenimiento con el objeto de disminuir el tiempo de infusión ${ }^{177}$.

7. Infusión periódica forzada: (técnica de pulse spray) es la Infusión vigorosa intratrombo para lacerar y fragmentar al mismo con el objeto de aumentar la superficie de lisis. Con este método, se logra mayor penetración del agente dentro del trombo y se acorta el periodo de infusión. Inicialmente el catéter se coloca unos centímetros por encima del extremo distal del trombo dejando una pequeña parte ocluida sin tratar. De esta manera, se evitaría cualquier posible micro-embolismo distal. La inyección forzada de agente lítico es suministrada manualmente a través de una jeringa de 2-5 cc, cada 20-30 s. Se suministra el agente lítico bajo presión a través de un catéter multiperforado. La presión creada contribuye a la lisis mecánica del trombo. Se logra la lisis del conducto en casi el $70 \%$ de los casos en una sola sesión dentro del laboratorio vascular ${ }^{178}$.

\section{Drogas trombolíticas:}

El agente utilizado actualmente es rtPA (activador del plasminógeno tisular).

La heparina es un complemento útil durante la trombolisis, aunque puede aumentar las complicaciones hemorrágicas y se puede infundir junto con la vaina permanente para prevenir el trombo peri-catéter durante la infusión del agente lítico.

La dosis total de rtPA se decide individualmente dependiendo de la duración y extensión de la oclusión arterial, el grado de isquemia y la edad del paciente. Hay varios protocolos, entre ellos:

- Una dosis en bolo de $4 \mathrm{mg}$ de rtPA, seguido de $0,5 \mathrm{mg} / \mathrm{h}$.

- $\quad$ 1-2 $\mathrm{mg} / \mathrm{h}$ durante las primeras $4 \mathrm{~h}$, seguido de 0,5-1,0 $\mathrm{mg} / \mathrm{h} .{ }^{179}$

- 0,001 a $0,02 \mathrm{mg} / \mathrm{kg} / \mathrm{h}$

Por supuesto que se debe evaluar al paciente en busca de antecedentes de relevancia y posibles fuentes embolígenas. También evaluar el lecho vascular con o sin enfermedad crónica o lecho vascular sano mediante examen clínico completo (pérdida de sensibilidad, debilidad muscular) y Doppler (audición de flujo arterial y venoso).

\section{Indicación única:}

Solamente miembro con señal de Doppler venoso audible y sin pérdida total de sensibilidad y capacidad motora. Por el contrario, si el paciente se presenta con profunda parálisis 
muscular (rigor muscular), pérdida sensitiva y señal de Doppler venoso inaudible y ausencia de relleno capilar, la indicación es quirúrgica (revascularización o amputación). La claudicación intermitente no es una indicación.

\section{Contraindicaciones para trombolisis dirigida por catéter:}

Absoluta: Hemorragia activa. Hemorragia intracraneana. Síndrome compartimental. Isquemia severa de miembro, que requiere cirugía inmediata.

Relativa: Trauma o cirugía mayor no vascular dentro de los últimos 10 días. HTA no controlada (>180 y/o $110 \mathrm{mmHg}$ ). Punción de vaso no compresible. Tumor intracraneal, Cirugía ocular reciente. Neurocirugía en los últimos 3 meses. Antecedente de alergia severa a contraste. Trauma intracraneal en los últimos 3 meses. Sangrado digestivo en los últimos 10 días. Falla hepática, con coagulopatía. Endocarditis. Embarazo/post parto. Hemorragia en retinopatía diabética. Expectativa de vida $<1$ año.

\section{Evidencia para el uso de trombolíticos:}

A pesar del uso generalizado de la trombolisis en la isquemia de miembros inferiores, una revisión sistemática reciente de los datos publicados encontró sólo diez informes de ensayos controlados aleatorios ${ }^{180}$.

La mayoría se refiere a la trombolisis de las oclusiones arteriales nativas. Sólo una de estas publicaciones, un subgrupo de pacientes identificados en el ensayo cirugía versus trombolisis para isquemia de extremidad inferior (STILE), informó específicamente los resultados de la cirugía vs trombolisis en pacientes con injertos de bypass ocluido de menos de seis meses de duración ${ }^{181}$.

Otros estudios de trombolisis para oclusiones de injertos de Bypass son retrospectivos o consisten en pequeños grupos de pacientes heterogéneos. Además de estos estudios, se mantuvo en el Reino Unido una gran base de datos nacional de trombolisis, la Auditoría Nacional de la Trombolisis en la Isquemia Aguda de Pierna (NATALI).

\section{Resultados de la trombolisis del injerto y factores pronósticos}

La base de datos NATALI demostró que la lisis exitosa se logró en el $70 \%$ de los intentos. La lisis completa fue lograda en el $48 \%$ y lisis parcial en el $22 \%$ de los pacientes. La permeabilidad al año de los injertos lisados fue del 33\%. En la "intención a tratar" esta cifra se redujo a $20 \%{ }^{182}$.

Una vez resuelto el trombo, es fundamental tratar la lesión subyacente. Esto mejora claramente la permeabilidad a largo plazo. Alternativamente, la lisis puede dirigir la terapia quirúrgica tradicional $y$ permitir un enfoque de acceso mínimo. De hecho, algunos estudios han demostrado que la hiperplasia intimal o injerto de vena, la estenosis puede ser mejor manejada por cirugía abierta que mediante las técnicas endovasculares. El injerto ocluido en el primer año suele tener menor permeabilidad post trombolisis, seguramente debido a que en este escenario es más importante la falla quirúrgica que la hiperplasia miointimal ${ }^{183}$.

\subsection{Trombo-aspiración}

Es otra alternativa a la cirugía. Fácil, bajo costo, sin dificultad técnica. Consiste en la utilización de un catéter con lumen grande (7-8 F o $5 \mathrm{~F}$ en arterias distales) que se conecta a una jeringa de 50 ml y que se aspira manualmente las veces que sea necesario.

Una alternativa eficaz es la utilización de la técnica combinada entre trombolíticos y trombectomía: trombolisis farmaco-mecánica.
El éxito primario de trombectomía sola es $31 \%$.

Con trombolisis farmaco-mecánica se logra hasta un $90 \%$ éxito primario, con $86 \%$ de salvataje del miembro y $58 \%$ de permeabilidad alejada a 4 años ${ }^{184,185}$.

\subsection{Trombectomía mecánica}

Se realiza mediante la maceración endovascular del trombo y su remoción, usando balones de Fogarty o Dispositivos dedicados para trombectomía percutánea que no se encuentran difundidos en nuestro medio.

Debido a la falta de estudios multicéntricos, randomizados y controlados, no existe clara indicación de su aplicación en el contexto de isquemia aguda. Aunque su uso podría estar avalado cuando existe contraindicación para el uso de agente trombolítico.

\section{Complicaciones del procedimiento endovascular:}

- Hemorragia mayor periférica (1-25\%)

- Hemorragia cerebral (0-2.5\%)

- $\quad$ Síndrome compartimental (1-10\%)

- Embolización distal post trombolisis (1-5\%) y post trombectomía mecánica (0-14\%)

- Perforación post trombectomía mecánica (0-5\%)

- Disección post trombectomía mecánica (0-6\%)

\section{Seguimiento:}

Medicación:

- Heparina posterior al procedimiento y luego anticoagulación oral (ACO) por 3-6 meses ${ }^{186}$.

- Antiplaquetario si la embolia fue la causa, cuando la lesión arteria no fue tratada o si fue necesario el implante de stent. La duración de la terapia antiplaquetaria aún está en revisión.

Inmediatamente posprocedimiento: eco-Doppler arterial (con índice tobillo brazo) para tener el valor basal y usarlo como referencia

\section{ANEXO IV. TRATAMIENTO ENDOVAS- CULAR DE LA ENFERMEDAD ANEURIS- MÁTICA DE MIEMBROS INFERIORES}

Los aneurismas en las arterias de la extremidad inferior son segundos en frecuencia solamente superados por los aneurismas de la aorta infrarrenal y de las arterias ilíacas. La mayoría de los aneurismas en las arterias femoral y poplítea son actualmente degenerativos o pseudoaneurismas postraumáticos, relacionados con cateterización o instrumentación. Los aneurismas verdaderos ocurren mucho más frecuentemente en hombres que en mujeres, en una proporción de 30:1. Además, los aneurismas verdaderos de las arterias femorales o poplíteas se asocian a menudo con aneurismas aórticos y aneurismas en la extremidad inferior contralateral. La asociación con aneurismas aórticos oscila entre el $50 \%$ y el $90 \%$ para los aneurismas femorales, aproximadamente el $30 \%$ hasta el $50 \%$ para los aneurismas poplíteos y hasta el $70 \%$ para los aneurismas poplíteos bilaterales. La bilateralidad es también frecuente, ocurriendo en aproximadamente el 25 al 50\% de los aneurismas femorales y del 50 al $70 \%$ de los aneurismas poplíteos. Por el contrario, hasta el $15 \%$ de los hombres con aneurismas aórticos poseen aneurismas femorales o poplíteos, pero esta combinación es un hallazgo raro en las mujeres. Por tanto, se encuentra indicado realizar una imagen adicional, como el ultrasonido Do- 
ppler, para evaluar la enfermedad aneurismática concomitante cuando se diagnostica un aneurisma aórtico o de extremidades inferiores.

Los aneurismas en los miembros inferiores son de importancia clínica debido a su potencialidad para causar isquemia grave que amenaza a las extremidades. Más raramente, tales aneurismas pueden romperse, en especial falsos aneurismas de la arteria femoral común. El tratamiento se indica aun cuando son asintomáticos; de ahí la importancia de la detección precoz y un conocimiento profundo de la asociación con otros aneurismas. Los aneurismas verdaderos sintomáticos se asocian en mayor grado con la pérdida de miembros debido a la prevalencia de embolización del trombo desde el interior del saco del aneurisma hacia las arterias más distales. Los médicos debemos considerar siempre la embolización de un aneurisma al evaluar la isquemia crítica de extremidades inferiores y al planificar las intervenciones. Ha habido cambios significativos en el tratamiento de estos aneurismas especialmente incluyendo nuevas terapias endovasculares.

\section{Aneurismas femorales}

Los aneurismas de la arteria femoral ocurren principalmente en la arteria femoral común y menos comúnmente en las arterias femoral profunda y superficial. La arteria femoral común (AFC) puede ser el sitio de aneurismas verdaderos y de pseudoaneurismas relacionados con instrumentación previa o procedimientos de revascularización previa. Los aneurismas verdaderos son menos frecuentes y se asocian con frecuencia a la arteria poplítea y a los aneurismas aórticos. En cualquier arteria, un aneurisma se define como una dilatación focal y fusiforme de la arteria, a 1,5 veces el diámetro normal del segmento adyacente. El tamaño normal de una AFC en los hombres es de aproximadamente $1 \mathrm{~cm}$ y $0,8 \mathrm{~cm}$ en las mujeres. Por tanto, la indicación quirúrgica para aneurismas es cuando alcanza los $2,5 \mathrm{~cm}$ de diámetro.

El pseudoaneurisma, por el contrario, suele aparecer como una dilatación sacular del vaso y tiene un estrecho cuello que representa un defecto en la pared del vaso debido a su instrumentación. El pseudoaneurisma es en realidad un borde de tejido fibroso que contiene trombo y flujo arterial en continuidad con un defecto en la arteria.

Los aneurismas verdaderos se encuentran predominantemente en hombres mayores (70 años o más) y están asociados con el tabaquismo y la hipertensión. La mayoría son degenerativos. Los aneurismas femorales verdaderos aislados son asintomáticos en el 30 al $40 \%$ de los pacientes y se detectan a menudo en el examen físico o Doppler. En otras situaciones, 30 a $40 \%$ causan dolor localizado o síntomas de compresión que dan lugar a dolor neuropático o edema de pierna. La presentación más frecuente en hasta el 65\% de los casos es la isquemia de las extremidades inferiores, incluida la claudicación o la isquemia crítica resultante de la embolización. La ruptura es una ocurrencia rara, que ocurre en aproximadamente en el $4 \%$ de los casos. No así los pseudoaneurismas, en donde la ruptura es una complicación esperable.

El Doppler es la modalidad de elección para el diagnóstico y la evaluación de los aneurismas de la arteria femoral. Es confiable y precisa. La angio-TC y la angio-RM también pueden utilizarse y pueden tener un valor adicional en la planificación de la reparación endovascular y cuando se necesitan medidas específicas para identificar la arteria normal proximal y distal al aneurisma. Ambas técnicas también pueden ser útiles para buscar aneurismas adicionales como en la aorta, arterias ilíacas, femoral contralateral o poplítea.

Todos los aneurismas femorales sintomáticos deben ser tratados para prevenir la embolización, trombosis, el empeoramiento de los síntomas locales por compresión y la ruptura. Aunque la historia natural de los aneurismas asintomáticos no está clara, se sugiere que los aneurismas femorales asintomáticos de más de $2,5 \mathrm{~cm}$ de diámetro deberían ser tratados, especialmente en pacientes de "buen riesgo quirúrgico". El tratamiento de los aneurismas verdaderos de AFC consiste en la exclusión del aneurisma con la interposición de un injerto. El tratamiento endovascular de los aneurismas de la AFC se ha limitado en gran medida a situaciones de emergencia o realizado como parte de un enfoque híbrido con un procedimiento quirúrgico abierto.

\section{Aneurismas poplíteos}

La mayoría de los aneurismas de la arteria poplítea (AAP) se desarrollan en la parte proximal o parte media de la arteria. Según las normas de 1991, en la práctica clínica la mayoría de los cirujanos utilizan $2 \mathrm{~cm}$ como el umbral de diámetro para definir un AAP.

Los AAP son bastante raros en la población general, aunque son los aneurismas de arteria periférica más comunes, representando al menos el $70 \%$ de ellos. Se encuentran casi exclusivamente en hombres. Un estudio de pacientes hospitalizados identificó que la incidencia de aneurismas de arteria femoral o poplítea era de 7,4 por 100.000 hombres y sólo 1,0 por 100.000 mujeres. Aproximadamente el 50\% de los pacientes tienen AAP bilateral y entre el $30 \%$ y el $50 \%$ de los pacientes puede tener una (AAA). Por el contrario, menos del 15\% de todos los pacientes con AAA tienen AAP coexistentes. En los pacientes tratados con aneurismas poplíteos aislados, la probabilidad de presentar otro aneurisma en algún sitio remoto, en un período de 10 años, se estima que es tan alto como el $50 \%$, por lo tanto, es mandatorio el rastreo de aneurismas en todos estos pacientes, en el primer control y de la vigilancia de por vida después del tratamiento.

La historia natural muestra una tasa media de crecimiento de $1,5 \mathrm{~mm} /$ año para AAP menores de $20 \mathrm{~mm}, 3 \mathrm{~mm} /$ año para aquellos con 20 a $30 \mathrm{~mm}$ y de $3,7 \mathrm{~mm} /$ año para aquellos mayores de $30 \mathrm{~mm}$. La hipertensión es el principal factor de riesgo asociado con el crecimiento de los aneurismas. En contraste con los AAA, los poplíteos rara vez se rompen, con una incidencia reportada de sólo 2,5\%. En los pacientes en los que se produce la ruptura, hay una tasa muy alta de pérdida de la extremidad. Cuando los AAP son sintomáticos, se manifiestan más típicamente como isquemia aguda o crónica debida a embolización distal o trombosis del aneurisma. Aunque puede ser difícil determinar el porcentaje real de pacientes con AAP que se convierten en sintomáticos a lo largo del tiempo, varias series de pacientes informan una alta incidencia de complicaciones tromboembólicas. La probabilidad de desarrollo de complicaciones aumenta con el tiempo, hasta el $74 \%$ en 5 años. Un tamaño mayor a $2 \mathrm{~cm}$, la presencia de trombo y un escaso flujo distal son factores de riesgo de complicaciones isquémicas entre los pacientes con AAP asintomáticas.

A pesar de que se puede encontrar incidentalmente, más de la mitad de los pacientes con AAP suelen tener síntomas en su presentación inicial. La isquemia es el síntoma más común y suele ser secundaria a la embolización o trombosis, y los síntomas pueden variar desde ser esencialmente ningu- 
na a claudicación mínima o isquemia aguda con compromiso de la vitalidad de la extremidad. No es infrecuente que los pacientes tengan oclusión de múltiples vasos tibiales secundarios a émbolos crónicos. El paciente con síntomas crónicos y una masa poplítea no pulsátil debe ser evaluado para descartar un AAP trombosado.

Con menor frecuencia, los pacientes presentan síntomas por compresión, que pueden incluir la vena (edema de las piernas, trombosis venosa profunda) o compresión nerviosa como resultado del efecto de masa asociado con grandes aneurismas. La ruptura es inusual.

Idealmente, el diagnóstico de AAP debe hacerse antes del inicio de las complicaciones que amenazan la extremidad. Los resultados del tratamiento quirúrgico son mejores en los pacientes asintomáticos y progresivamente peores en aquellos con síntomas isquémicos crónicos o isquemia avanzada. Debe ser pensado el diagnóstico de AAP en cualquier momento en que se sienta un pulso poplíteo prominente o amplio en el examen físico. Un AAP es más probable que se encuentre en hombres con AAA conocido, AAF o AAP contralateral. Del mismo modo, un pulso poplíteo prominente con gangrena del pie ipsilateral en un hombre no diabético debe descartar el diagnóstico de un posible AAP. Una masa poplítea no pulsátil en un paciente con síntomas isquémicos debe conducir a sospechar una AAP trombosado. El examen físico, sin embargo, se ha demostrado poco fiable, con resultados falsos positivos y falsos negativos.

Las principales modalidades de imagen utilizadas para el diagnóstico de los AAP son el eco Doppler, Angio-TC y Angio-RM. La Angio-TC es una modalidad de imagen muy útil y precisa para el diagnóstico y evaluación de los AAP. La Angio-TC puede demostrar con precisión el tamaño, la cantidad de trombo y los vasos de entrada y salida. También puede ser extremadamente útil en la planificación de la reparación abierta o endovascular.

La angiografía digital se utiliza junto con los exámenes radiológicos antes mencionados para determinar la permeabilidad de los vasos de entrada y salida y para la planificación operativa.

\section{Indicaciones para el tratamiento}

Se acepta que todos los pacientes con AAP sintomáticas y aquellos con $2 \mathrm{~cm}$ o más de diámetro deben ser considerados para tratamiento. Por el contrario, algunos autores sugieren que todos los aneurismas poplíteos deben ser reparados una vez encontrados, independientemente del tamaño, debido a la alta tasa de complicaciones y pérdida de miembros. La planificación de la cirugía y la decisión de proceder con un abordaje endovascular, abierto o híbrido depende de la anatomía del paciente, la edad y las comorbilidades. El sistema arterial del paciente debe ser visualizado desde la aorta abdominal hasta los vasos del pie. La opción para la reparación electiva incluye un enfoque endovascular (puramente percutáneo o híbrido con exposición de la arteria femoral), utilizando una endoprótesis o un enfoque abierto que utiliza un bypass arterial.

El tratamiento endovascular tiene el beneficio de no requerir anestesia general o regional y, por lo tanto, la ventaja teórica de disminuir el riesgo cardíaco. El procedimiento se puede realizar ya sea mediante una punción percutánea o una pequeña incisión para exponer la AFC o AFS. Los criterios de selección anatómicos para la reparación endovascular incluyen un segmento proximal y distal normal (zonas de aterrizaje) de al menos $2 \mathrm{~cm}$ de longitud (sin una gran discrepancia de tamaño entre las zonas de aterrizaje proximal y distal) falta de tortuosidad vascular extensa y un aneurisma que no sea extremadamente grande (lo que haría que una endoprótesis sea propensa a torsión o desplazamiento).

Una endoprótesis cubierta autoexpandible de nitinol es la más utilizada en este territorio. El abordaje endovascular se fundamenta en la anatomía arterial. Lógicamente la ausencia de una vena adecuada puede dirigir la indicación, al igual que la asociación de enfermedad oclusiva extensa en el territorio poplíteo, virando la indicación hacia el tratamiento convencional. Desde el punto de vista técnico se enumeran los siguientes aspectos:

- Zona de anclaje proximal y distal de al menos $2 \mathrm{~cm}$ de longitud

- Evitar el anclaje o la superposición en el área de flexión

- No realizar sobredimensionado de la endoprótesis

- Evitar o minimizar la superposición de segmentos

- Al menos un vaso de salida

- Despliegue distal a proximal

En experiencia de un centro local 22 pacientes fueron tratados mediante esta técnica ( 21 hombres, edad media $72 \pm 11$ años, rango 57-96 años), en los que se implantó la endoprótesis cubierta autoexpandible de nitinol, bajo anestesia local y abordaje mediante disección de la arteria femoral superficial proximal. La duración media de la estancia hospitalaria fue de $2 \pm 1,8$ días (rango, 3-11 días). Ninguno de los pacientes se perdió en el seguimiento (media $36 \pm 19,4$ meses, rango 6-96 meses). No se detectó oclusión, fractura o endofuga tipo I, con una supervivencia global a los 4 años del $74 \%$ (análisis de Kaplan-Meier).

En la actualidad, el tratamiento puede tener a la trombolisis como primer paso para la repermeabilización de un AF o AP trombosado, lo cual permite la apertura de vasos de salida también ocluidos, determinando la aparición de un vaso para la anastomosis distal del bypass conformando de esta manera un abordaje híbrido.

\section{BIBLIOGRAFÍA}

5. Verhaeghe R. [Epidemiology and prognosis of peripheral obliterative arteriopathy]. Drugs. 1998;56 Suppl 3:1-10.

6. Pande RL, Perlstein TS, Beckman JA, et al: Secondary prevention and mortality in peripheral artery disease: National Health and Nutrition Examination Study, 1999 to 2004, Circulation 124:17-23, 2011.

7. Selvin E, Erlinger TP: Prevalence of and risk factors for peripheral arterial disease in the United States: Results from the National Health and Nutrition Examination Survey, 1999-2000, Circulation 110:738-753, 2004.

8. Diehm C, Schuster A, Allenberg JR, et al: High prevalence of peripheral arterial disease and co-morbidity in 6880 primary care patients: cross-sectional study, Atherosclerosis 172:95-105, 2004
9. Hirsch AT, CriquiMH, Treat-Jacobson D, et al:Peripheral arterial disease detection, awareness, and treatment in primary care, JAMA 286:1317-1324, 2001.

10. Dormandy J, Heeck L, Vig S. dormandy j. The natural history of claudication: risk to life and limb. sem vasc surg 12:123-7.1999. TASC II, Eur J Vasc Endovasc Surg,33, 2007.

11. Bailey MA, Griffin KJ, Scott DJ1.Clinical assessment of patients with peripheral arterial disease Semin Intervent Radiol. 2014 Dec;31(4):292-9. doi: 10.1055/s 0034-1393964

12. Fisicaro M. [Why are cardiologists to be concerned about obliterating arterial disease of the lowerleg?]. Ital Heart J Suppl. 2003 Apr;4(4):306-18

13. Garimella PS1, Hart PD, O'Hare A, DeLoach S, Herzog CA, Hirsch AT. Periphera 
artery disease and CKD: a focus on peripheral artery disease as a critical component of CKD care. Am J Kidney Dis. 2012 Oct;60(4):641-54. doi: 10.1053/j. ajkd.2012.02.340. Epub 2012 May 5.

14. Rose GA: The diagnosis of ischaemic heart pain and intermittent claudication in field surveys, Bull Word Health Organ 27:645-658, 1962.

15. Marius Rac-Alua.M , Luminita llutab, Gubernac SM, Sinescud C.. The Role of Ankle-Brachial Index for Predicting Peripheral Arterial Disease Journal of Clinical Medicine 2014; 9(3): 295-302

16. LijmerJG, HuninkMG, van derDungen JJ, LoonstraJ, SmitAJ.ROC analysis of noninvasivetests forperipheral arterial disease. UltrasoundMed Biol 1996;22:391-8.

17. Jelnes R, Gaardsting O, Hougaard Jensen K, Baekgaard N, Tønnesen KH, Schroeder T. Fate in intermittent claudication: outcome and risk factors. Br Med J (Clin Res Ed) 1986;293:1137-40.

18. McDermottMM, CriquiMH, LiuK, GuralnikJM, GreenlandP, Martin GJ, PearceW . Lower ankle/brachial index, as calculated by averaging the dorsalis pedis and posterior tibial arterial pressures, and association with leg functioning in peripheral arterial disease. JJ Vasc Surg. 32 (6): 1164-71.)

19. Fowkes FG, Murray GD, Butcher l, et al: Ankle brachial index combined with Framingham risk score to predict cardiovascular events and mortality: a meta-analysis, JAMA 300:197-208, 2008.

20. Sikkink CJ, van Asten WN, van't Hof MA, et al: Decreased ankle/brachial índices in relation to morbidity and mortality in patients with peripheral arterial disease, VascMed 2:169-173, 1997.

21. Ouriel K, MCDonnell AE, Metz CE, Zarins CK. Critical evaluation of stress testing in the diagnosis of peripheral disease. Surgery 1982,91:686-93.

22. Hiatt WR, Hirsch AT, Regensteiner JG, et al: Clinical trials for claudication. Assessment of exercise performance, functional status, and clinical end points. Vascular Clinical Trialists, Circulation 92:614-621, 1995.

23. Koelemay MJ, den Hartog D, Prins MH, Kromhout JG, Legemate DA, Jacobs MJ. Diagnosis of arterial disease of the lower extremities with duplex ultrasonography. BrJ Surg 1996; 83:404-9.

24. Bandyk DF, Chauvapun JP. Duplex ultrasound surveillance can be worthwhile after arterial intervention. Perspect Vasc Surg Endovasc Ther 2007; 19:354-9.

25. Ferris BL, Mills JL Sr, Hughes JD, Durrani T, Knox R. Is early postoperative duplex scan surveillance of leg bypass grafts clinically important? J Vasc Surg 2003; 37:495-500.

26. Lofberg AM, Karacagil S, Hellberg A, et al: The role of duplex scanning in the selection patients with critical lower-limb ischemia for infrainguinal percutaneous transluminal angioplasty, Cardiovascular Intervent Radiol 24:229-232, 2001.

27. Mandolfino T, Canciglia A, D'Alfonso $M$, et al:Infrainguinal revascularization based on duplex ultrasound arterial mapping, Int Angiol 25:256-260, 2006.

28. Baum RA, Rutter CM, Sunshine JH, Blebea JS, Carpenter JO, Dickey KV, et al. Multicenter trial to evaluate vascular magnetic resonance angiography of the lower extremity. American College of Radiology Rapid Technology Assessment Group. JAMA 1995; 274:875-80

29. Prince MR, Yucel EK, Kaufman JA, Harrison DC, Geller SC. Dynamic gadolinium-enhanced three-dimensional abdominal MR arteriography. J Magn Reson Imaging 1993; 3:877-81.

30. Tatli S, Lipton MJ, Davison BD, Skorstad RB, Yucel EK. From the RSNA refresher courses: MR imaging of aortic and peripheral vascular disease. Radiographics 2003; 23 (Spec No.):S59-S78.

31. MellM, Tefera G, Thornton F, Siepman D, Turnipseed W. Clinical utility of time-resolved imaging of contrast Kinetics (TRICKS) magnetic resonance angiography for infrageniculate arterial occlusive Disease. J Vasc Surg 2007; 45:543-8.

32. Dorenbeck U, SeitzJ, VolkM, et al: Evaluation of arterial by pass graft of the pelvic and lower extremities with gadolinium-enhanced magnetic resonance angiography: comparison with digital subtraction angiography, Invest Radiol 37:6064,2002.

33. Loewe C, Cejna M, Schoder M, et al: Contrast material-enhanced, moving-table MR angiography versus digital subtraction angiography for surveillance of peripheral arterial by pass graft, J Vasc Interv Radiol 14:1129-1137, 2003.

34. Steffens JC, Schafer FK, Oberscheid B, et al: Bolus-chasing contrast-enhanced 3DMRA of the lower extremity. Comparison with intraarterial DSA, Acta Radiol 44:185-192, 2003.

35. Heijenbrok-KalMH,KockMC,HuninkMG.Lowerextremity arterial disease:multidetector CT angiography meta-analysis. Radiology 2007; 245:433-9.

36. Met R, Bipat S, Legemate DA, Reekers JA, Koelemay MJ. Diagnostic performance of computed tomography angiography in peripheral arterial disease: a systematic review and meta-analysis. JAMA 2009:301:415-24.

37. lezzi R, Santoro M, Marano R, DiStasiC, DattesiR, Kirchin M, et al. Low-dosemultidetector CT angiography in the evaluation of infrarenal aorta and peripheral arterial occlusive disease. Radiology 2012; 263:287-98.
38. Heinrich MC, Kuhlmann MK, Grgic A, Heckmann M, Kramann B, Uder M. Cytotoxic effects of ionic high-osmolar, nonionic monomeric, and nonionic iso-osmolar dimeric iodinated contrast media on renal tubular cells in vitro. Radiology 2005;235:843-9.

39. Seelinger E, SendeskiM, Rihal CS, Persson P. Contrast-induced kidney injury: mechanisms, risk factors, and prevention. Eur Heart J 2012; 33:2007-15.

40. Antithrombotic Trialists' Collaboration. Collaborativemeta-analysis of randomised trials of antiplatelet therapy for prevention of death, myocardial infarction, and stroke in high risk patients.BMJ. 2002;324:71-86.

41. Berger JS, KrantzMJ, Kittelson JM, Hiatt WR. Aspirin for the prevention of cardiovascular events in patients with peripheral artery disease: a meta-analysis of randomized trials. JAMA. 2009 May 13;301(18):1909-19.

42. CAPRIESteering Committee. Arandomised, blinded, trial of clopidogrelversus aspirin in patients at risk of ischaemic events (CAPRIE). CAPRIESteering Committee. Lancet. 1996 Nov 16:348(9038):1329-39.

43. BhattDL, FoxKA, HackeW,BergerPB, BlackHR, Boden WE, etal. CHARISMAInvestigators. Clopidogrel and aspirin versus aspirin alonefor the prevention of atherothrombotic events. NEngl J Med. 2006 Apr 20;354(16):1706-17.

44. BhattDL, FlatherMD, HackeW, etal. CHARISMA Investigators. Patients with prior myocardial infarction, stroke, or symptomatic peripheral arterial disease in the CHARISMA trial. J Am Coll Cardiol. 2007 May 15;49(19):1982-8.

45. Johnson WC, Williford WO. Department of Veterans Affairs Cooperative Study \#362 Benefits, morbidity, and mortality associated with long-term administration of oral anticoagulant therapy to patients with peripheral arterial bypass procedures: a prospective randomized study. J Vasc Surg. 2002;35:413-21.

46. AnandS, YusufS, Xie C, Pogue J, Eikelboom J, BudajA, Sussex B, Liu L, Guzman R, Cina C, Crowell R, Keltai M, Gosselin G. Oral anticoagulant and antiplatelet therapy and peripheral arterial disease. N Engl J Med. 2007 Jul 19;357(3):217-27.

47. Allemang MT, Rajani RR, Nelson PR, Hingorani A, Kashyap VS. Prescribing patterns of antiplatelet agents are highly variable after lower extremity endovascular procedures. Ann Vasc Surg.2013;27:62-67.

48. Armstrong EJ, Anderson DR, Yeo KK, Singh GD, Bang H, Amsterdam EA, et al. Association of dual-antiplatelet therapy with reduced major adverse cardiovascular events in patients with symptomatic peripheral arterial disease. J Vasc Surg. $2015 \mathrm{Jul} ; 62(1): 157-165$

49. Tepe G, Bantleon R, Brechtel K, Schmehl J, Zeller T, Claussen CD, et al. Management of peripheral arterial interventions with mono or dual antiplatelet therapy--the MIRROR study: a randomised and double-blinded clinical trial. Eur Radiol. 2012 Sep;22(9):1998-2006.

50. StroblFF, BrechtelK, SchmehlJ,ZellerT,ReiserMF, Claussen CD, etal. Twelve-month results of a randomized trial comparing mono with dual antiplatelet therapy in endovascularly treated patients with peripheral artery disease. J Endovasc Ther. 2013 Oct;20(5):699-706

51. Robertson L, GhouriMA, Kovacs F. Antiplatelet and anticoagulant drugs for prevention of restenosis/reocclusion following peripheral endovascular treatment. Cochrane Database Syst Rev. 2012 Aug 15;(8):CD002071.

52. Tepe G, Laird J, Schneider P, Brodmann M, Krishnan P, Micari A, et al.

53. IN.PACT SFA Trial Investigators. Drug-coated balloon versus standard percutaneous transluminal angioplasty for the treatment of superficial femoral and popliteal peripheral artery disease: 12-month results from the IN.PACTSFA randomized trial. Circulation. 2015 Feb 3;131(5):495-502.

54. Rosenfield K, Jaff MR, White C, Rocha-Singh K, Mena-Hurtado C, Metzger DC, et al. LEVANT 2 Investigators. Trial of a Paclitaxel-Coated Balloon for Femoropopliteal Artery Disease. N Engl J Med. 2015 Jul 9:373(2):145-53.

55. Zeller T, Baumgartner I, Scheinert D, Brodmann M, Bosiers M, Micari A, et al. IN.PACT DEEP Trial Investigators. Drug-eluting balloon versus standard balloon angioplasty for infrapopliteal arterial revascularization in critical limb ischemia: 12-month results from the IN.PACTDEEPrandomized trial.J Am Coll Cardiol. 2014 Oct 14;64(15):1568-76.

56. Liistro F, Porto I, Angioli P, Grotti S, Ricci L, Ducci K, et al. Drug-eluting balloon in peripheralintervention forbelow the knee angioplasty evaluation (DEBATE-BTK): a randomized trial in diabetic patients with critical limb ischemia. Circulation. 2013 Aug 6;128(6):615-21.

57. Scheinert D, Katsanos K, Zeller T, et al; ACHILLES Investigators. A prospective randomized multicenter comparison of balloon angioplasty and infrapopliteal stenting with the sirolimus-eluting stent in patients with ischemic peripheral arterial disease: 1-year results from the ACHILLES trial. J Am Coll Cardiol. 2012;60(22):2290-2295.

58. Bosiers M, Scheinert D, Peeters P, Torsello G, Zeller T, Deloose K, et al. Randomized comparison of everolimus-eluting versus bare-metal stents in patients with critical limb ischemia and infrapopliteal arterial occlusive disease. J Vasc Surg. 2012 Feb;55(2):390-8. 
59. Rastan A, Tepe G, Krankenberg H, Zahorsky R, Beschorner U, Noory E, et al. Sirolimus-eluting stents vs. bare-metal stents for treatment of focal lesions in infrapopliteal arteries: a double-blind, multi-centre, randomized clinical trial. Eur Heart J. 2011 Sep;32(18):2274-81.

60. DudaSH, Bosiers M, LammerJ,ScheinertD,ZellerT, TielbeekA, et al. Sirolimus-eluting versus bare nitinolstentfor obstructive superficial femoral artery disease: the SIROCCO II trial. J Vasc Interv Radiol. 2005 Mar;16(3):331-8.

61. Dake MD, Ansel GM, JaffMR, Ohki T, Saxon RR, Smouse HB, et al. Zilver PTX Investigators. Sustained safety and effectiveness of paclitaxel-eluting stents for femoropopliteallesions: 2-yearfollow-up from the Zilver PTX randomized and single-arm clinical studies. J Am Coll Cardiol. 2013 Jun 18;61(24):2417-27.

62. Lammer J, Bosiers M, Zeller T, Schillinger M, Boone E, Zaugg MJ, et al. First clinical trial of nitinol self-expanding everolimus-eluting stent implantation for peripheral arterial occlusive disease. J Vasc Surg. 2011 Aug;54(2):394-401.

63. Pilger E, Lammer J, Bertuch H, Stark G, Decrinis M, Pfeiffer KP, et al. Nd:YAG laser with sapphire tip combined with balloon angioplasty in peripheral arterial occlusions. Long-term results. Circulation. 1991 Jan;83(1):141-7

64. DoDD,Mahler F.Low-dose aspirin combined with dipyridamoleversus anticoagulants after femoropopliteal percutaneous transluminal angioplasty. Radiology. 1994 Nov; 193(2):567-71.

65. lida O, Yokoi H, Soga Y, Inoue N, Suzuki K, Yokoi Y, et al. STOP-IC investigators. Cilostazol reduces angiographic restenosis after endovascular therapy for femoropopliteal lesions in the Sufficient Treatment of Peripheral Intervention by Cilostazol study. Circulation. 2013 Jun 11;127(23):2307-15.

66. Soga Y, Yokoi H, Kawasaki T, Nakashima H, Tsurugida M, Hikichi Y, et al. Efficacy of cilostazol after endovascular therapy for femoropopliteal artery disease in patients with intermittent claudication. J Am Coll Cardiol. 2009 Jan 6;53(1):48-53.

67. BrownJ, Lethaby A, Maxwell H, WawrzyniakA, Prins MH. Antiplateletagents for preventing thrombosis after peripheral arterial bypass surgery. Cochrane Database Syst Rev 2008:4:CD000535.

68. Efficacy of oral anticoagulants compared with aspirin after infrainguinal bypass surgery (The Dutch Bypass Oral Anticoagulants or Aspirin Study): a randomised trial. Lancet. 2000 Jan 29;355(9201):346-51.

69. Kashyap VS, Pavkov ML, Bena JF, et al. The management of severe aortoiliac occlusive disease: endovascular therapy rivals open reconstruction. J Vasc Surg. 2008;48(6):1451-7. 1457, e1-3.

70. DeVries SO, HuninkMG. Results of aortic bifurcation grafts for aortoiliac occlusive disease: a meta-analysis. J Vasc Surg. 1997;26(4):558-69.

71. Chiesa R, MaroneEM, TshombaY, et al. Aortobifemoral bypass grafting using expanded polytetrafluoroethylenestretch grafts in patients with occlusive atherosclerotic disease. Ann Vasc Surg. 2009;23(6):764-9.

72. Upchurch GR, DimickJB, Wainess RM, et al. Diffusion of new technology in health care: the case of aorto-iliac occlusive disease. Surgery. 2004;136(4):812-18.

73. Jongkind V, Akkersdijk GJM, Yeung KK, Wisselink W. A systematic review of endovascular treatment of extensive aortoiliac occlusive disease. I Vasc Surg. 2010;52(5):1376-83.

74. Leville CD, Kashyap VS, Clair DG, et al. Endovascular management of iliac artery occlusions: extending treatment to TransAtlantic Inter-Society Consensus class C and D patients. J Vasc Surg. 2006:43(1):32-9.

75. Chang RW, Goodney PP, BaekJH, et al. Long-term results of combined common femoral endarterectomy and iliac stenting/stent grafting for occlusive disease. J Vasc Surg. 2008;48(2):362-7.

76. PulliR, Dorigo W, Fargion A, et al. Early andlong-term comparison ofendovascular treatment ofiliac artery occlusions and stenosis. J Vasc Surg. 2011;53(1):92-8.

77. Indes JE, Mandawat A, Tuggle CT, et al. Endovascular procedures for aorto-iliac occlusive disease are associated with superior short-term clinical and economic outcomes compared with open surgery in the inpatient population. J Vasc Surg. 2010;52:1173-1179.

78. Indes JE, PfaffMJ, Farrokhyar F, et al. Clinical outcomes of 5358 patients undergoing direct open bypass or endovascular treatment for aortoiliac occlusive disease: asystematicreview and meta-analysis. J Endovasc Ther. 2013;20:443-455.

79. Leville CD, Kashyap VS, Clair DG, et al. Endovascular management of iliac artery occlusions: extending treatment to TransAtlantic Inter-Society Consensus class C and D patients. J Vasc Surg. 2006;43:32-39.

80. Tetteroo, E., van der Graaf, Y., Bosch, J.L., van Engelen, A.D., Hunink, M.G., Eikelboom, B.C. et al, Randomised comparison of primary stent placement versus primary angioplasty followed by selective stent placement in patients with iliac-artery occlusive disease. Dutch lliac Stent Trial Study Group. Lancet. 1998;351:1153-1159.

81. Bosch, J.L., Hunink, M.G. Meta-analysis of the results of percutaneous transluminal angioplasty and stent placement for aortoiliac occlusive disease. Radiology. 1997;204:87-96.
82. Sabri SS, Choudhri A, Orgera G, et al. Outcomes of covered kissing stent placement compared with baremetal stent placement in the treatment of atheroscleroticocclusive disease at the aortic bifurcation. J Vasc IntervRadiol.2010;21:9951003

83. Grimme FA, Goverde PA, Van Oostayen JA, et al. Covered stents for aortoiliac reconstruction of chronic occlusive lesions. J Cardiovasc Surg (Torino). 2012;53:279-289.

84. Mwipatayi BP, Thomas S, Wong J, et al. A comparison of covered vs bare expandable stents for the treatment of aortoiliac occlusive disease. J Vasc Surg. 2011;54:1561-1570.

85. Humphries MD, Armstrong E, Laird J, et al. Outcomes of covered versus bare-metal balloon-expandable stents for aortoiliac occlusive disease. J Vasc Surg. 2014;60:337-343.

86. Kudo T, Chandra FA, Ahn SS. The effectiveness of percutaneous transluminal angioplasty for the treatment of critical limb ischemia: a 10-year experience. J Vasc Surg 2005:41(3):423-35.discussion 435

87. Jones WS, Patel MR, Dai D, et al. Temporal trends and geographic variation of lower-extremity amputation in patients with peripheral artery disease: results from U.S. Medicare 2000-2008. J Am Coll Cardiol 2012;60(21):2230-6

88. Balmer H, Mahler F, Do DD, Triller J, Baumgartner, et al. Balloon angioplasty in chronic critical limb ischemia: factors affecting clinical and angiographic outcome.J Endovasc Ther. 2002 Aug;9(4):403-10.

89. Schillinger M, SabetiS, Loewe C, et al. Balloon angioplastyversus implantation of nitinol stents in the superficial femoral artery. NEngl J Med. 2006;354:1879-1888.

90. Dick P, Wallner H, Sabeti S, et al. Balloon angioplasty versus stenting with nitino stents in intermediate length superficial femoral artery lesions. Catheter Cardiovasc Interv. 2009;74:1090-1095.

91. Schillinger M, Sabeti S, Dick P, Amighi J, Mlekusch W, Schlager O, Loewe C, Cejna M, Lammer J, Minar E. Sustained benefit at 2 years of primary femoropopliteal stenting compared with balloon angioplasty with optional stenting. Circulation 2007; 115:2745-2749.

92. Laird JR, Katzen BT, Scheinert D, et al. Nitinol stent implantation vs. balloon angioplasty for lesions in the superficial femoral and proximal popliteal arteries of patients with claudication: three-yearfollow-up from the RESILIENT randomized trial. J Endovasc Ther. 2012;19:1-9

93. Schlager O, Dick P, Sabeti S, et al. Long-segment SFA stenting — the dark sides: in-stent restenosis, clinical deterioration, and stent fractures. J Endovasc Ther. 2005; 12:676-684

94. DakeMD,Ansel GM, JaffMR, etal. Paclitaxel-elutingstents showsuperiorityto baIloon angioplasty and baremetalstents infemoropopliteal disease:twelve-month zilver ptx randomized study results. Circ Cardiovasc Interv 2011;4(5):495-504 44.

95. Dake MD, Ansel GM, Jaff MR, et al. Sustained safety and effectiveness of paclitaxel-eluting stents for femoropopliteal lesions. J Am Coll Cardiol 2013;61(24): 2417-27

96. Durable Clinical Effectiveness With Paclitaxel-Eluting Stents in the Femoropopliteal Artery: 5-Year Results of the Zilver PTX Randomized Trial. Circulation, March 11-2016

97. Giacoppo D, CasseseS, HaradaY, etal.Drug-coated balloon versus single balloon angioplasty for the treatment of femoropopliteal artery disease: an updated sys tematic review and a meta-analysis of randomized clinical trials. JACC Cardiovasc Interv 2016:9 (16): 1731-42

98. Jia X, Zhang J, Zhuang B, et al. Acotec Acotec drug-coated balloon catheter: a randomized, multicenter, controlled clinical study in femoropopliteal arteries: evidence from the Acoart I. trial. JACC Cardiovasc Interv 2016; 9 (18): 1941-49.

99. Scheinert D, Schmidt A, Zeller T, et al. German center of subanalysis of the global randomized study LEVANT2 of the balloon coated with Lutonixdrugs in the treatment of femoropopliteal occlusive disease. J Endovasc Ther 2016;23 (3): 409-16.

100. Tepe G, Schnorr B, Albrecht T, et al. Angioplasty of the femoral-popliteal arteries with drug-coated balloons: five years of follow-up of the THUNDER test. JACC Cardiovasc Interv 2015; 8 (1 PtA): 102-08.

101. Elmahdy MF, Buonamici P, Trapani M, et al. Long-term primary patency rate after implantation of self-expanding nitinol stents in patients with femoropopliteal long and total occlusions (TASC IIC\&D) Lesions: (Retrospectivestudy). Heart Lung Circ 2016. Epub.

102. Tepe G, Beschorner U, Ruether C, et al. Drug-eluting balloon therapy for femoropopliteal occlusive disease: Predictors of the outcome with aspecial emphasis on calcium. J Endovasc Ther 2015; 22: 727-33.

103. Fanelli F, Cannavale A, Gazzetti M, et al. Evaluation of calcium loading and impacton drug-eluting balloons in peripheral arterial disease. Cardiovasc Intervent Radiol 2014; 37: 898-907.

104. Fanelli F. Real world record Lutonix Global SFA-oral presentation. CIRSE 2016 
105. ScheinertD. Registration In.PACT Global - oral presentation. EuroPCR 2015.

106. Albertal M, Abizaid A, Munoz JS, et al. A novel mechanism that explains the early loss of light after balloon angioplasty for the treatment of intrastent restenosis. Am J Cardiol 2005: 95 (6): 751-54

107. Kinstner CM, LammerJ, Willfort-Ehringer A, etal. Paclitaxel-releasing balloon Faced with standard balloon angioplasty in intra-stent restenosis of the superficial femoral artery and proximal popliteal artery: results of 1 year of the PACUBA trial. JACC Cardiovasc Interv 2016; 9 (13): 1386-92

108. Laird JR, Yeo KK. The treatment offemoropopliteal in-stentrestenosis:back to the future. J Am Coll Cardiol. 2012;59:24-25

109. KrankenbergH, TüblerT,Ingwersen M, etal. Drug-coated balloonversusstandard balloonforrestenosis ofthesuperficialfemoral artery in thestent:thein-stentrandomizedfemoral artery restenosis (FAIR) trial. Circulation 2015; 132 (23):2230-36.

110. Stabile E, Virga V, Alemme L, et al. Drug-eluting balloon for the treatment of intrastent restenosis of the superficial femoral artery. J Am Coll Cardiol 2012; 60 (18): 1739-42.

111. Tendera M, Aboyans V, Bartelink ML, et al. ESC guidelines on the diagnosis and treatment of peripheral arterial diseases: Document covering atherosclerotic disease of the extracranial carotid and vertebral, mesenteric, renal arteries, upper and lower extremities: the Working Group on the diagnosis and treatment of arterial diseases peripherals of the European Society of Cardiology (ESC). Eur Heart J 2011;32 (22) 2851-906.

112. Katsanos K, Tepe G, Tsetis D, Fanelli F. Standards of practice for stent and angioplasty with superficial and popliteal femoral artery. Cardiovasc Intervent Radiol 2014; 37 (3): 592-603.

113. Bosiers M, Deloose K, Callaert J, et al. Superiority of stent-grafts for in-stent restenosis in the superficial femoral artery: twelve-month results from a multicenter randomized trial. J Endovasc Ther. 2015;22:1-10

114. Van Den Berg JC, Pedrotti M, Canevascini R. Endovascular treatment of intrastent restenosis using excimer laser angioplasty and drug elution balloons. J Cardiovasc Surg (Torino) 2012;53 (2):215-22.

115. Van Den Berg JC, Pedrotti M, Canevascini R. Stent restenosis: results of debulking in the medium term with excimer laser and drug-eluting balloons: sustained benefit? I Invasive Cardiol 2014; 26 (7):333-37.

116. Dippel E, Makam P, Kovach R, et al. Randomized controlled study of excimer laser atherectomy for treatment of femoropopliteal in-stent restenosis: initial results from the EXCITE ISR trial (Excimer Laser Randomized Controlled Study for Treatment of Femoropopliteal In-Stent Restenosis). JACC Cardiovasc Interv. 2015;8:92-101

117. JaffM. Full clinical cohort of the IN.PACT Global study. Presented at: VIVA 16; September 18-22, 2016; Las Vegas, Nevada

118. Norgren L, Hiatt WR, Dormandi JA, Nehler MR, Harris KA, Fowkes FG. Inter-society consensus for the management of peripheral artery disease (TASC II). J Vasc Surg 2007;45 (Supp/ S): S5-S67

119. RookeTWetal.2011 ACCF/AHA. Focused Update of the Guideline for the Management of Patients With Peripheral Artery Disease (Updating the 2005 Guideline). AReport of the American College of Cardiology Foundation/American Heart Association Task Force on Practice Guidelines. Circulation 2011; 124:2020-2045.

120. Bradbury AW, Adam DJ, Bell J, Forbes JF, Fowkes FG, Gillespiel, Ruckley CV, Raab GM;BASIL trial Participants. Bypassversus Angioplastyin Severelschaemia of the Leg (BASIL) trial: Analysis of amputation free and overall survival by treatmentreceived. J Vasc Surg 2010; 51:185-315.

121. JaffMR, White ChJ, Hiatt WR, Fowkes GR, Dormandy J, Razavi M, Reekers J, Norgren L. An Update on Methods for Revascularization and Expansion of the TASC Lesion Classification to Include Below-the-KneeArteries: A Supplement to the Inter-Society Consensus for the Management of Peripheral Arterial Disease (TASC II) The TASC Steering Committee*. Cathet Cardiovasc Interven 2015; 86:611-625.

122. Tendera M, Aboyans V, et.al. ESC Committee for Practice Guidelines. ESC Guidelines on the diagnosis and treatment of peripheral artery diseases: Document covering atherosclerotic disease of extracranial carotid and vertebral, mesenteric, renal, upper and lower extremity arteries: the Task Force on the Diagnosis and Treatment of Peripheral Artery Diseases of the European Society of Cardiology (ESC). Eur Heart J. 2011;32:2851-906.

123. BakalCW,SprayregenS, ScheinbaurnK, CynarnonJ,VeithFJ.Percutaneous Transluminal Angioplasty ofthe Infrapopliteal Arteries:Results in 53Patients.AIR 1990; 154:171-174.

124. lida O, Soga Y, Hirano K, Kawasaki D, Suzuki K, Miyashita Y, Terashi H, Uematsu M. Long-term results of directand indirectendovascular revascularization based on the angiosomeconceptin patients with critical limbischemiapresenting with isolated below-the-kneelesions. J Vasc Surg 2012; 55:363-70.

125. van Overhagen H, Spiliopoulos S, Tsetis D. Below-the-kneeInterventions. Cardiovasc Intervent Radiol 2013; 36:302-311.
126. Dorros G, Jaff MR, Murphy KJ, Mathiak L. The Acute Outcome of Tibioperoneal Vessel Angioplasty in 417 Cases With Claudication and Critical Limb Ischemia. Cathet Cardiovasc Diagn 1998; 45:251-256.

127. Faglia E, Dalla Paola L, Clerici G, Clerissi J, Graziani L, Fusaro M, Gabrielli L, Losa S, Stella A, Gargiulo M, Mantero M, Caminiti M, Ninkovic S, Curci V, Morabito A. Peripheral Angioplasty as the First-choice Revascularization Procedure in Diabetic Patients with Critical Limb Ischemia: Prospective Study of 993 Consecutive Patients Hospitalized and Followed Between 1999 and 2003. Eur J Vasc Endovasc Surg 2005; 29:620-627.

128. Graziani L, Silvestro A, Bertone V, Manara E, Andreini R, Sigala A, Mingardi R, De Giglio R. Vascular involvement in diabetic subjects with ischemic foot ulcer: a new morphologic categorization of disease severity. Eur J Vasc Endovasc Surg 2007; 33:453-60

129. Rocha-Singh KJ, Zeller T, Jaff MR. Peripheral Arterial Calcification: Prevalence, Mechanism, Detection, and Clinical Implications. Cathet Cardiovasc Interven 2014;83:E212-E220

130. Sauguet A, Leger P. Tools \& Techniques: Below the knee interventions. Eurolntervention 2012; 7(9): 1120-3.

131. Liistro F, Porto I, Angioli P, Grotti S, Ricci L, DucciK, Falsini G, Ventoruzzo G, Turín F, BellandiG, BologneseL. Drug-Eluting Balloon in Peripheral InterventionforBelow the Knee Angioplasty Evaluation (DEBATE-BTK) A Randomized Trial in Diabetic Patients With Critical Limb Ischemia. Circulation. 2013; 128:615-621.

132. Fanelli F, Cannavale A, Gazzetti M, Lucatelli P, WIderk A, Cirelli C, d'Adamo A, Salvatori FM. Calcium burden assessment and impact on drug-eluting balloons in peripheral arterial disease. Cardiovasc Intervent Radiol 2014;37 (4):898-907.

133. Siablis D, Kitrou PM, Spiliopoulos S, Katsanos K, Karnabatidis D. Paclitaxel-Coated Balloon Angioplasty Versus Drug-Eluting Stenting for the Treatment of Infrapopliteal Long-Segment Arterial Occlusive Disease. The IDEASRandomized Controlled Trial. J Am Coll Cardiol Intv 2014; 7:1048-56.

134. Kawarada O, Fujihara M, Higashimori A, Yokoi Y, Honda Y and Fitzgerald PJ. Predictors of Adverse Clinical Outcomes Alter Successful Infrapopliteal Intervention. Catheter Cardiovasc Interv 2012;80(5):861-71.

135. Faglia E, Clerici G, Clerissi J, Gabrielli L, et al. Early and five-year amputation and survival rate of diabeticpatients with criticallimbischemia: data of a cohortstudy of 564 patients.Eur J Vasc Endovasc Surg. 2006 Nov;32(5):484-90.

136. Reinecke H, Unrath M, Freisinger E, Bunzemeier H, etal. Peripheral arterial disease and critical limb ischaemia: still poor outcomes and lack of guideline adherence. Eur Heart J. 2015 Apr 14;36(15):932-8.

137. Dormandy JA, Rutherford RB. Management of peripheral arterial disease (PAD). TASC Working Group. TransAtlantic Inter-Society Consensus (TASC). J Vasc Surg 2000; 31:S5-S34

138. Dick F, Diehm N, Galimanis A, Husmann M, Schmidli I, Baumgartner I. Surgical or endovascular revascularization in patients with critical limb ischemia: influence of diabetes mellitus on clinical outcome. J Vasc Surg 2007;45:751-761

139. Faglia E, Clerici G, Losa S, Tavano D, Caminiti M, et al. Limb revascularization feasibility in diabetic patients with critical limb ischemia: results from a cohort of 344 consecutive unselected diabetic patientsevaluated in 2009. Diabetes Res Clin Pract. 2012 Mar;95(3):364-71.

140. Adam DJ, Beard JD, Cleveland T, Bell J, Bradbury AW, Forbes JF, Fowkes FG, Gillepsie I, Ruckley $C V$, Raab G, Storkey H. Bypass versus angioplasty in severe ischaemia of the leg (BASIL): multicentre, randomised controlled trial. Lancet 2005;366:1925-1934

141. lida O, Nakamura M, Yamauchi Y, Kawasaki D, Yokoi Y, et al. Endovasculartreatment for infrainguinal vessels in patients with critical limb ischemia: OLIVE registry, a prospective, multicenter study in Japan with 12-month follow-up. Circ Cardiovasc Interv. 2013 Feb;6(1):68-76

142. Soga Y1, Mii S, Aihara H, Okazaki J, Kuma S, et al. Comparison of clinical outcome after bypass surgery vs. endovascular therapy for infrainguinal artery disease in patients with critical limb ischemia.Circ J. 2013;77(8):2102-9.

143. Graziani L, Silvestro A, Bertone V, Manara E, Andreini R, Sigala A, Mingardi R, De Giglio RVascular involvement in diabetic subjects with ischemic foot ulcer: A new morphologic categorization of disease severityEur J Vasc Endovasc Surg, 2007

144. Gray BH, Grant AA, Kalbaugh CA, BlackhurstD, Langan EM III, Taylor SA, Cull DL The impact of isolated tibial disease on outcomes in the critical limb ischemicpopulation. Ann Vasc Surg, 2010

145. Sadek M, Ellozy SH, Turnbull IC. Improved outcomes are associated with multilevel endovascular intervention involving the tibial vessels compared with isolated tibial intervention. J Vasc Surg, 2009

146. Attinger CE, Evans KK, Bulan E, et al. Angiosomes of the foot and ankle and clinical implications for limb salvage: reconstruction, incisions, and revascularization. Plast Reconstr Surg 2006; 117 (7 Suppl):261S-93S 20. 
147. Alexandrescu V-A, Hubermont $G$, Philips Y, et al. Selective primary angioplasty following an angiosome model of reperfusion in the treatment of wagner 1-4 diabetic foot lesions: practice in a multidisciplinary diabetic limb service. J Endovasc Ther 2008; 15(5):580-93

148. Neville RF, Attinger CE, Bulan EJ, et al. Revascularization of a specific angiosome forlimb salvage: does the targetarterymatter? Ann Vasc Surg 2009;23(3):367-73

149. Kabra A, Suresh KR, Vivekanand V, et al. Outcomes of angiosome and non-angiosome targeted revascularization in critical lower limb ischemia. J Vasc Surg 2013;57(1):44-9

150. AlexandrescuV, Vincent G, AzdadK, et al. A reliable approach to diabeticneuroischemic foot wounds: below-the-knee angiosome-oriented angioplasty. JEndovasc Ther 2011;18(3):376-87

151. Liistro F, Portol, AngioliP, et al. Drug-eluting balloon in peripheral intervention for below the kneeangioplastyevaluation (debate-btk): arandomized trial in diabetic patients with critical limb ischemia. Circulation 2013;128(6):615-21

152. Zeller T, Baumgartner I, Scheinert D, et al. Drug-eluting balloon versus standard balloon angioplasty for infrapopliteal arterial revascularization in critical limb ischemia: 12-month results from the IN.PACT DEEP randomized trial. J Am Coll Cardiol 2014; 64(15):1568-7

153. Rastan A, Tepe G, Krankenberg H, et al. Sirolimus-eluting stents vs. bare-metal stents for treatment offocallesions in infrapopliteal arteries: a double-blind, multi-centre, randomized clinical trial. Eur Heart J 2011:32(18):2274-81

154. Rastan A, BrechtelK, Krankenberg H, et al. Sirolimus-eluting stents for treatment of infrapopliteal arteries reduce linical eventrate compared to bare-metal stents: long-term results from a randomized trial. J Am Coll Cardiol 2012;60(7):587-91

155. Bosiers M, Scheinert D, Peeters $P$, et al. Randomized comparison of everolimus-eluting versus bare-metal stents in patients with critical limb ischemia and infrapopliteal arterial occlusive disease. J Vasc Surg 2012;55(2):390-8

156. Díaz JA, Villegas $M$, Tamashiro $G$, et al. Flexions of the popliteal artery: dynamic angiography. J Invasive Cardiol 2004;16:712-5.

157. Diaz JA, Miceli MH, Villegas M, Tamashiro G, et al. Dynamic anatomy of the popliteal artery: hinge point and accessory flexions. VascularDisease Management 2005; 2March/April.

158. Avisse C, Marcus C, Ouedraogo T, Delattre JF, Menanteau B, Flament JB. Anatomo-radiological study of the popliteal artery during knee flexion. Laboratoire d'Anatomie, Surg Radiol Anat 1995;17(3):255-62.

159. Mozersky DJ, SumnerDS, Hokanson DE, Strandness DEJr. Transcutaneous measurement of the elastic properties of the human femoral artery. Circulation 1972 Nov:46(5):948-55.

160. Zocholl G, ZapfS, Schild H, Thelen M. Functional angiography of the arteries near the kneejoint: consequences for stent implantation? Rofo 1990 Dec;153(6):658-62.

161. Tamashiro GA, Tamashiro A, Villegas MO, et al. Flexions of the popliteal artery: technical considerations of femoropopliteal stenting. J Invasive Cardiol 2011;23(10):431-3.

162. Kroger K, Santosa F, Goyen M. Biomechanical incompatibility of popliteal stent placement. J Endovasc Ther 2004;11(6):686-94.

163. VolpatoMG,MetzgerPB, FolinoMC, et.al. Tratamientoendovasculardelosaneurismas de la arteria poplitea. Rev Bras Cardiol Invasiva 2014; 22(4):375-81.

164. Cambiaghi T, Spertino A, Bertoglio L, Chiesa R. Fracture of a Supera Interwoven Nitinol Stent After Treatment of Popliteal Artery Stenosis. J Endovasc Ther. 2017 Jun;24(3):447-449

165. Shackles C, Rundback JH, Herman K, David Y, et al. Above and Below Knee Femoropopliteal VIABAHN ${ }^{\oplus}$. Catheter Cardiovasc Interv 2015 Apr;85(5):859-67.

166. Garcia L, JaffMR, MetzgerC, Sedillo G, PershadA, ZidarF, Patlola R, Wilkins RG, Espinoza A, Iskander A, KhammarGS, Khatib Y, Beasley R, Makam S, Kovach R, Kamat S, Leon LRJr, Eaves WB, Popma JJ, Mauri L, Donohoe D, Base CC, Rosenfield K; SUPERB Trial Investigators. Wire-Interwoven Nitinol Stent Outcome in the Superficial Femoral and Proximal Popliteal Arteries: Twelve-Month Results of the SUPERB Trial. Circ Cardiovasc Interv. 2015 May;8(5). pii: e000937.

167. AboyansV,RiccoJB, etal.ESCScientific DocumentGroup.2017ESCGuidelineson theDiagnosis and Treatment of Peripheral Arterial Diseases, in collaboration with the European Society for Vascular Surgery (ESVS): Document covering atherosclerotic disease of extracranial carotid and vertebral, mesenteric, renal, upperand lowerextremity arteries Endorsed by: the European StrokeOrganization(ESO)The Task Force for the Diagnosis and Treatment of Peripheral Arterial Diseases of the European Society of Cardiology (ESC) and of the European Society for Vascular Surgery (ESVS). Eur Heart J. 2018Mar 1;39(9):763-816.
168. Rooke TW, Hirsch AT, et al. American College of Cardiology Foundation Task Force; American Heart Association Task Force. Management of patients with peripheral artery disease (compilation of 2005 and 2011 ACCF/AHA Guideline Recommendations): a report of the American College of Cardiology Foundation American Heart Association Task Force on Practice Guidelines. J Am Coll Cardiol. 2013 Apr 9;61(14):1555-70

169. Mills JL, Conte MS, et al. Society for Vascular Surgery Lower Extremity Guidelines Committee. The Society for Vascular Surgery Lower Extremity Threatened Limb Classification System: risk stratification based on wound, ischemia, and foot infection (WIfI). J Vasc Surg. 2014 Jan;59(1):220-34.

170. Bradbury AW, Adam DJ, Bell J, Forbes JF, Fowkes FG, Gillespiel, Ruckley CV, Raab GM; BASIL trial Participants. Bypass versus Angioplasty in Severelschaemia of the Leg (BASIL) trial: A description of the severity and extent of disease using the Bollinger angiogram scoring method and the TransAtlantic Inter-Society Consensus II classification. J Vasc Surg. 2010 May; 51 (5 Suppl):32S-42S

171. Iyer SS, Dorros G, Zaitoun R. Retrograde recanalization of an occluded posterior tibial artery by using a posterior tibial cutdown: two cases report. Cathet Cardiovasc Diagn 1990 Aug;20(4):251-3.

172. Montero-BakerM,SchmidtA,BraunlichS, etal. Retrogradeapproach forcomplex popliteal and tibioperoneal occlusions. J Endovasc Ther 2008 Oct; 15(5):594-604

173. BottiCFJr, Ansel GM, SilverMJ, et al. Percutaneous retrograde tibial access in limb salvage. J Endovasc Ther 2003 Jun; 10(3):614-8.

174. Advanced Tibial Pedal Access Manual. J.AMustapha

175. Edwar JE, Taylor LM, Porter JM Treatment of failed lower extremity bypass grafts with new autogenous vein bypass grafting. J Vasc Surg, 1990, 11: 136-45.)

176. Comerota AJ, Weaver FA, Hosking JD et al. Results of a prospective, randomised trial of surgery versus thrombolysis for occluded lower extremity bypass grafts. Am J Surg, 1996, 172:105-12

177. Guest P, Buckenham T. Thrombolysis of the occluded prosthetic graft with tissue type plasminogen activator - technique, results and problems in 23 patients. Clin Radiol, 1992, 46:381-6.

178. Kessel DO, Berridge DC, Robertson I (2004) Infusion techniques for peripheral arterial thrombolysis. Cochrane Database Sys tRev 1:CD000985

179. Braithwaite BD, Buckenham TM, Galand RB et al (1997) A prospective randomized trial of high-dose versus low-dose tissue plasminogen activator infusion in the management of acute limb ischemia. Br J Surg 84:646-650

180. Hess H, Ingrisch H, MietaschkA et al (1982) Locallow-dose thrombolytic therapy of peripheral arterial occlusions. N Engl J Med 307:1627-1630

181. TraughberPD, CookPS, Miclos TJ et al (1987) Intra-arterial fibrinolytic therapy for popliteal and tibial artery obstruction: comparison ofstreptokinase to urokinase. Am J Roentgenol 149:443-456

182. HYER. J., TURNER C., VALII K. et al. Is thrombolysis of occluded popliteal bypass grafts worth while? J VascSurg, 1994, 4:588-96

183. Grip, O., Kuoppala, M., Acosta, S., Wanhainen, A., Åkeson, J. and Björck, M. (2014), Outcome and complications after intra-arterial thrombolysis for lower limb is chaemiawithorwithoutcontinuous heparin infusion. BrJSurg, 101:1105-1112. doi:10.1002/bjs.9579

184. Palfreyman S J., Booth A., Michaels J. A. A systematic review of intra-arterial thrombolytic therapy for lower limb ischaemia. Eur J VascEndovascSurg, 2000, 19:143-57

185. Comerota A. J., Weaver F. A., Hosking J. D. et al. Results of a prospective, randomised trial of surgery versus thrombolysis for occluded lower extremity bypass grafts. Am J Surg, 1996, 172:105-12

186. Galland R. B., Magee T. R.,Whitman B. et al. Patency following successful thrombolysis of occluded vascular grafts. Eur J Vasc Endovasc Surg, 2001, $22: 157-60$

187. Nackman G. B.,Walsh D. B., Fillinger M. F. et al. Thrombolysis of occluded infrainguinal vein grafts: Predictors of outcome. JVascSurg, 1997, 6: 1023-31

188. Karnabatidisetal.:Quality Improvement Guidelines 1135123 thelegs:howmuch thrombolysis is needed? Eur J Vasc Endovasc Surg 20:41-46

189. Rilinger N, LutzP, Ha berle HJ, Tom czak R, LiewaldF, Orend KH, Pfeifer T, Friedrich JMPercutaneous aspiration thromboembolectomy in thetreatment of acuteocclusion of the lower leg arteries. Aktuelle Radiol 4(5):253-255

190. Norgren L, Hiatt WR, Dormandy JA et al. Inter-Society Consensus for the Management of Peripheral arterial Disease (TASC II). Eur J Vasc Endovasc Surg 33(Suppl 1):S1-S75 